Illinois State University

ISU ReD: Research and eData

Theses and Dissertations

7-7-2017

\title{
Modeling The Influence of El Niño on Parasite Transmission in Sand Crab Populations and Seabird Abundance Along the Californian Coast
}

\author{
Aboubacar Dio Seck \\ Illinois State University, seckdio@hotmail.com
}

Follow this and additional works at: https://ir.library.illinoisstate.edu/etd

Part of the Mathematics Commons

\section{Recommended Citation}

Seck, Aboubacar Dio, "Modeling The Influence of El Niño on Parasite Transmission in Sand Crab Populations and Seabird Abundance Along the Californian Coast" (2017). Theses and Dissertations. 775. https://ir.library.illinoisstate.edu/etd/775

This Thesis is brought to you for free and open access by ISU ReD: Research and eData. It has been accepted for inclusion in Theses and Dissertations by an authorized administrator of ISU ReD: Research and eData. For more information, please contact ISUReD@ilstu.edu. 


\title{
MODELING THE INFLUENCE OF EL NIÑO ON PARASITE TRANSMISSION IN SAND CRAB POPULATIONS AND SEABIRD ABUNDANCE ALONG THE CALIFORNIAN COAST
}

\begin{abstract}
Aboubacar Dio Seck
54 Pages

Pacific mole crabs (Emerita analoga) are one of the most important and abundant invertebrates in sandy beach environments. Consequently, they are a common food source for seabirds and sea otters. Since the mole crab serves as the primary intermediate host for acanthocephalan parasites, they have been linked to a number of mortality events. It is currently estimated that $13-16 \%$ of deaths in the threatened California sea otter population have been caused by infection. In addition, unusually high loads of acanthocephalan parasites have been linked to episodic deaths of thousands of surf scoters. Studies suggest that acanthocephalan development and transmission may be strongly effected by weather patterns. In this research paper, we introduce a system of differential equations for parasite transmission between surf scoter, sand crab, and sea otter populations. Temperature-dependent parameters within the model allow us to examine the role of climate oscillation in El Niño(EN) and La Niña(LN) years on abundances of infected hosts. We applied t-test to crab prevalence data, and we performed sensitivity analysis, and Floquet theory on our model to conclude that EN events increase the prevalence of infected crabs.
\end{abstract}

KEYWORDS: ENSO, Disease Dynamics, Floquet Theory, Sensitivity Analysis 
MODELING THE INFLUENCE OF EL NIÑO ON PARASITE TRANSMISSION

IN SAND CRAB POPULATIONS AND SEABIRD ABUNDANCE

ALONG THE CALIFORNIAN COAST

ABOUBACAR DIO SECK

A Thesis Submitted in Partial

Fulfillment of the Requirements

for the Degree of

MASTER OF SCIENCE

Department of Mathematics

ILLINOIS STATE UNIVERSITY 
(C) 2017 Aboubacar Dio Seck 
MODELING THE INFLUENCE OF EL NIÑO ON PARASITE TRANSMISSION

IN SAND CRAB POPULATIONS AND SEABIRD ABUNDANCE

ALONG THE CALIFORNIAN COAST

ABOUBACAR DIO SECK

COMMITTEE MEMBERS:

Olcay Akman, Chair

James Peirce

Fusun Akman 


\section{ACKNOWLEDGMENTS}

This thesis would have never been accomplished without the assistance and dedicated involvement in every step throughout the process of my committee members. I would like to thank you very much for your support and understanding over these past years. Firstly, I would like to thank my thesis advisor Dr. Olcay Akman and his wife Dr. Fusun Akman. Their offices were always open whenever I ran into a trouble spot or had a question about anything during my undergraduate and graduate years. Beyond their continuous support and advice, they consistently allowed this paper to be my own work, and steered me in the right direction whenever they thought I needed it. I would also like to extend my gratitude to Dr. James Peirce for his continual help and his guidance since the beginning of this journey. His expertise and comments were very important to narrow down this thesis research. I also take this opportunity to thank my friends and my family. My eternal gratitude goes to my dear parents Badicko Sango and Abass Seck, my wonderful siblings Mohamed, Fatimata, Rokia, Binta and Kadidiatou, my beautiful wife Fatoumata Kante, and my lovely daughter Fatimata Leyla for providing me with unconditional support and continuous encouragement throughout my years of study and through the process of researching and writing this thesis. This accomplishment would not have been completed without them. Finally, I must express my very profound gratitude to the Almighty Allah for His mercy, His protection, and His guidance.

A. D. S. 


\section{CONTENTS}

Page

ACKNOWLEDGMENTS CONTENTS

ii

TABLES

FIGURES

CHAPTER

I. INTRODUCTION 1

Primary Hosts 1

Intermediate Host and Parasite Species $\quad 2$

Parasite Life Cycle 4

Climate Effects on Transmission Between Hosts $\quad 6$

Question Under Investigation $\quad 9$

$\begin{array}{ll}\text { II. MODEL DEVELOPMENT } & 10\end{array}$

$\begin{array}{ll}\text { Models } & 10\end{array}$

$\begin{array}{ll}\text { Model Parameters } & 10\end{array}$

Differential Equation Model Development 11

$\begin{array}{ll}\text { Susceptible and Infected Surf Scoters } & 12\end{array}$

Susceptible and Infected Mole Crabs 13

Susceptible and Infected Sea Otters 15

$\begin{array}{ll}\text { Temperature Dependence } & 16\end{array}$

EN and LN Differences 20

$\begin{array}{ll}\text { Model Analysis } & 20\end{array}$ 
Initial Conditions $\quad 24$

III. APPLICATIONS 26

Data Description 26

$\begin{array}{ll}\text { EN-LN Significance T-Test } & 27\end{array}$

Implementation $\quad 30$

EN Influence on Infected Crabs Prevalence 33

$\begin{array}{ll}\text { Conclusion } & 35\end{array}$

IV. CONCLUDING REMARKS 36

$\begin{array}{ll}\text { Future Directions } & 37\end{array}$

$\begin{array}{ll}\text { REFERENCES } & 39\end{array}$

APPENDIX A: MATHEMATICA CODES 47

APPENDIX B: DATA SUMMARY 53 


\section{TABLES}

Table Page

1. Summary of species parameters, their biological meaning, and the source 11

2. Summary of the sensitivity index for the model parameters 23

3. EN and LN temperature differences 28

4. Difference within and between EN and LN 28

5. Summary of the two-sample t-test 30

6. EN linear regression slope test summary 34 


\section{FIGURES}

Figure $\quad$ Page

1. This figure shows the definitive hosts of the acanthocephalan parasite 2

2. This figure shows Acanthocephala and its intermediate host 4

3. Acanthocephala life cycle [17] 5

4. An overview of the years of EN and LN episodes since 1950 [16] 6

5. ENSO episodes with their intensity and the duration since 1950 [16] 7

6. Acanthocephala life cycle and the transmission map derived from it 12

7. Temperature as a function of time from January 1950 to January $2017 \quad 19$

8. Graph representing the function $\gamma(T)$ over 10 years 20

9. Mean and standard error of infected crabs prevalence (LiMPETS data) 27

10. This figure compares the temperatures in 1981, 1982, and in 1984

11. Number of susceptible and infected birds during migration season 31

12. Percentage of crab populations from simulation and from observed data 32

13. Relationship between infected crab prevalence and the temperature 33 


\section{CHAPTER I}

\section{INTRODUCTION}

\section{Primary Hosts}

Surf scoter (Melanitta perspicillata, Figure 1(a)) is a large North American sea duck measuring between 19 to 24 inches in length that lives both in marine habitats and freshwater, with a mean lifespan of 9.5 years [1]. The number of these bird populations have declined appreciably over the past 30 to 60 years in North America. The decline is estimated approximately 40-80\%, depending the location and timeframe [2]. Since 1990, there has been some evidence that the population size of these birds has been stabilized, with a slight decline. Unfortunately, causes for these declines are not well known. The possible causes are climate change and its impacts on birds' nesting habitats, such as the advancement of the seasonal phenology, the alteration of prey availability, or the shifts in the cycle of oceanic regimes [2].

On the Pacific Coast, preliminary studies $[3,4,5,6]$ indicate that the survivorship is higher at major molting sites, but lower during winter, depending on body mass, age, and location. During non-breeding periods, surf scoters migrate to coastal sites where they are more exposed to human activities (especially hunting, oil spills and other pollutions/contaminations), new competitive species (prey or/and predator), as well as the presence of some infectious diseases. Around 40 to $50 \%$ of the surf scoter populations are estimated to overwinter in San Francisco [7, 8, 9, 10], where the probability of being infected is considerable.

Sea otters (Enhydra lutris, Figure 1(b)) are small marine mammals with a lifespan of up to 23 years [1] listed under the Marine Mammal Protection and Endangered Species 
Acts of the 1970s. They represent the beauty, the health, and the diversity of marine life along the Californian coast. Considered a keystone species, they are very important to the marine ecosystem's health and stability [11]. In fact, otters are predators for sea urchins and other invertebrates that can destroy kelp forests, an important component of the marine biodiversity ecosystem. Kelp forests are of primary importance for the wide diversity of marine animals, protect coastline from storm surges, and more importantly, absorb a huge amount of harmful carbon dioxide from our atmosphere. A massive death of sea otters will surely impact not only the balance of marine ecosystem but also our global ecosystem. Toxicity, habitat degradation, white shark attacks, food limitation, and parasitism are some of the causes that drive the increase of sea otter mortality [12].

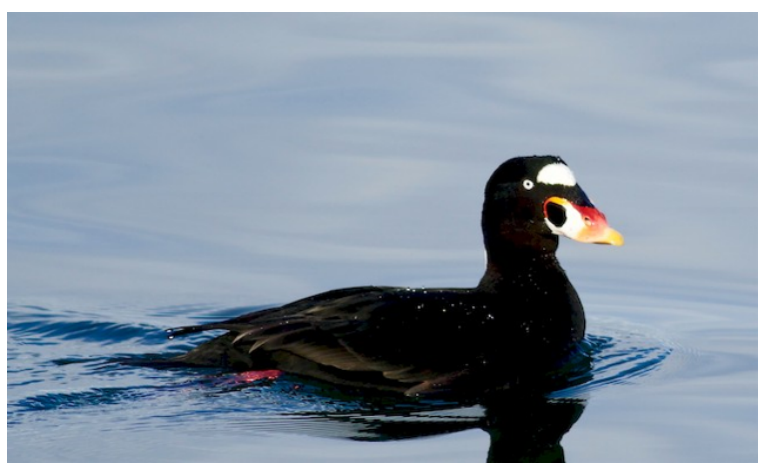

(a) Surf scoter [13].

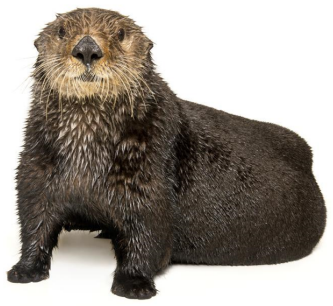

(b) Sea otter [11].

Figure 1: This figure shows the definitive hosts of the acanthocephalan parasite

\section{Intermediate Host and Parasite Species}

Widely distributed geographically, sand crabs (Emerita analoga, Figure 2(b)), are found along the entire Pacific Coast of North and South America, from Alaska to Chile $[20,21]$. They have five pairs of legs and can swim, crawl, and burrow, all backwards, but stay buried most of the times in the sand. Its takes sand crabs 1-7 seconds to bury 
themselves completely, depending on their size [23]. E. analoga live burrowed a few centimeters beneath the sand in the region of the beach between the highest and lowest reach of the waves, called the wash zone, at any given time [19]. Depending on environmental factors, their number on a beach can vary considerably from year to year. Sand crabs are one of the most important and abundant food sources for fishes, birds, and sea otters in sandy beach environments and serve as a primary host for the acanthocephalan parasites [23]. Flores and Sanchez reported that an increase in the number of acanthocephalan parasites in the crabs increase the burrowing time [24]. Thus, having slower hiding time, the crabs' risk of being dislodged by swash velocities and swept away into the open ocean increases, and therefore, they become more exposed to predators. Acanthocephala (Figure 2(a)) is a phylum of parasitic thorny-headed or spiny-headed worms, characterized by the presence of an evertable proboscis, a feeding or sucking organ, and armed with spines used to pierce and hold the gut wall of its host [17]. It has a complex life cycle that requires multiple hosts, which may include invertebrates (e.g., crabs), fishes, amphibians, birds, and mammals [17]. Like many parasites, Acanthocephala is a manipulative parasite. Recent studies show that manipulative parasites can alter their host behavior via apoptosis, causing the inflammation of the central nervous system and perturbing the biochemical communication [25] in order to increase the chance of completing their life cycle. 


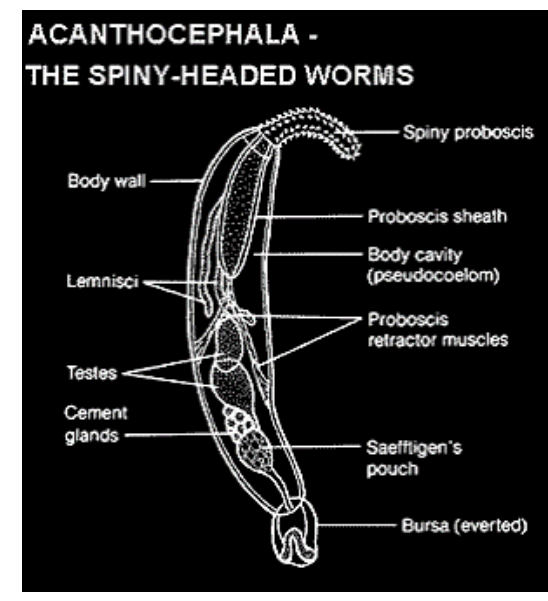

(a) Acanthocephala [15].

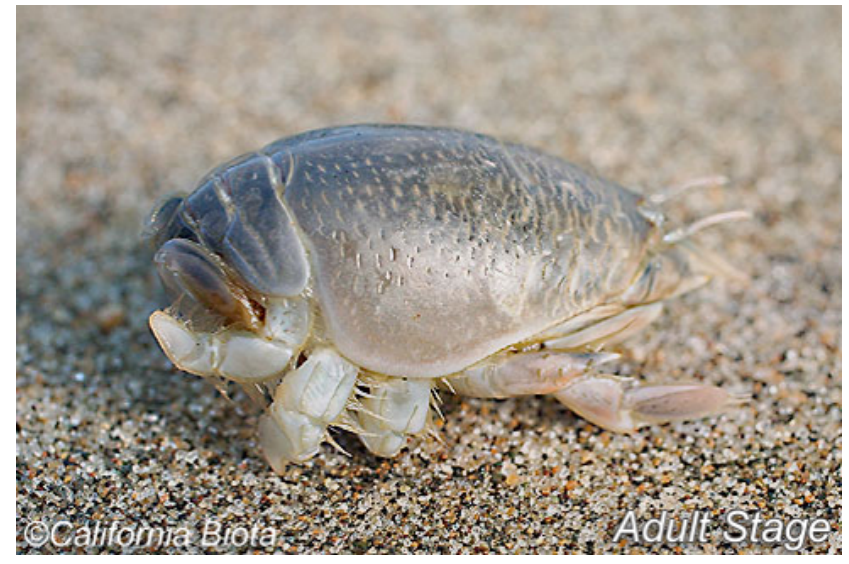

(b) Sand crab [14].

Figure 2: This figure shows Acanthocephala and its intermediate host

\section{Parasite Life Cycle}

Acanthocephalan parasites utilize crustaceans as intermediate and vertebrates as definitive hosts to complete their reproduction. The first stage of the parasite life cycle, from egg to juvenile, takes place in the secondary host (e.g., sand crabs, lobster), and they develop to adult inside the digestive tracts of the primary host (e.g., sea otters or birds), where they become reproductive. In the beginning, the adult parasite releases eggs in the ocean, where they float freely until they get eaten by a suitable intermediate host, such lobsters in Canada or pacific mole crabs in California. Once ingested, the eggs develop into a juvenile parasite, called a cystacanth [17]. After a brief delay, the parasite alters the behavior of the crabs through adaptive manipulation [26, 27, 28], by making crabs infectious and more exposed to surf scoters, sea otters, and other crab predators. Thus, the attraction of a definitive host is indispensable to complete the reproduction cycle. The definitive hosts are infected when they ingest an infectious prey such as crabs. Various coastal birds and marine mammals are definitive hosts for acanthocephalan parasites, allowing the parasites to become adults and reproduce. Inside the small intestine of the 
definitive host, the cystacanth emerges from its cyst and matures into an adult worm. Adult acanthocephalan parasites produce eggs that are released via the birds' feces back into the ocean to continue the cycle. Among the seabirds that are infected by acanthocephalan parasites are gulls, willets, sanderlings, and sea ducks, such as eiders, and surf scoters. Acanthocephalan parasites also affect California sea otters as well, but the latter are a dead-end host because the parasites cannot reproduce in otters. Once ingested, acanthocephalan parasite disease may cause death in the final hosts [17].

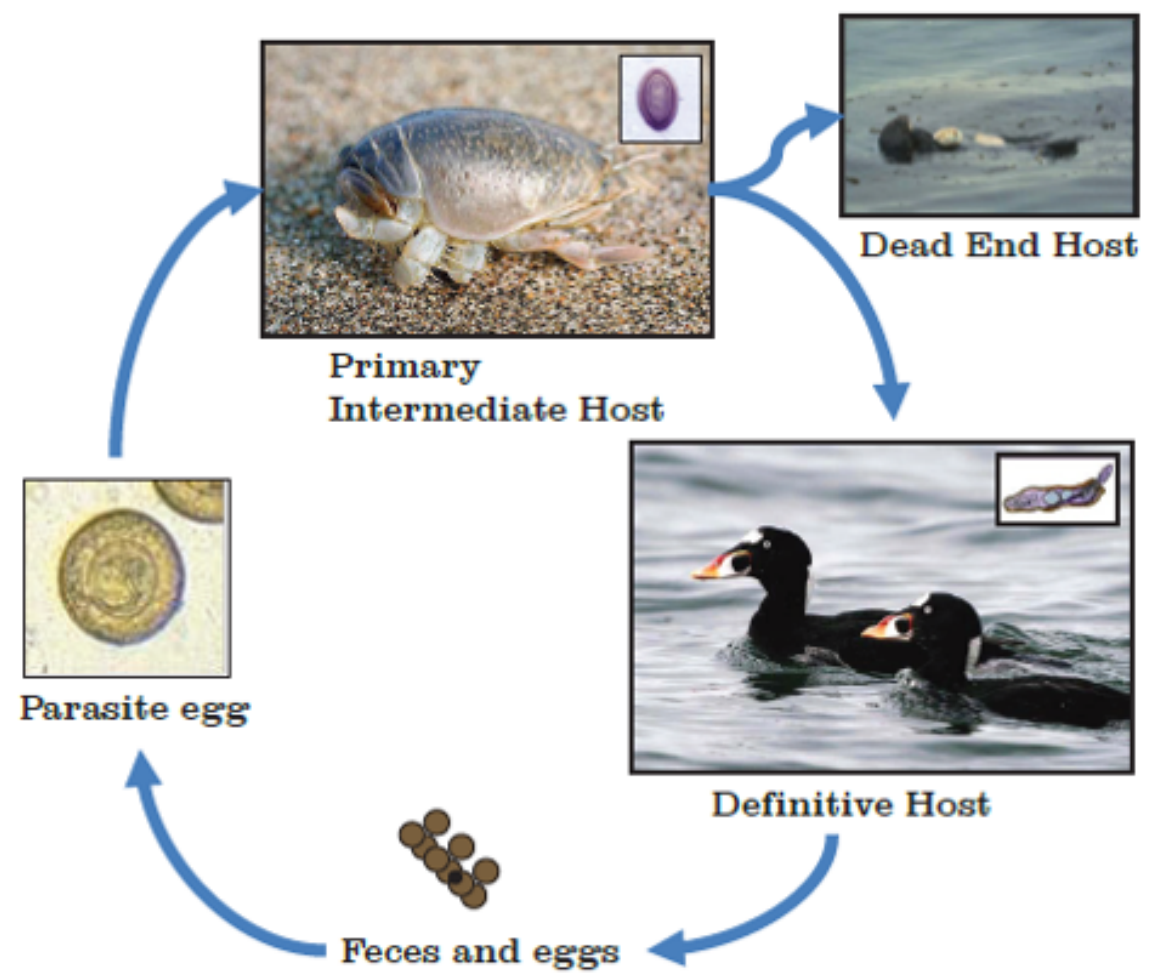

Figure 3: Acanthocephala life cycle [17]

Figure 3 shows the reproduction cycle of an acanthocephalan parasite through a crab, a surf scoter, and a sea otter [18]. As mentioned above, sea otters are dead-end hosts, 
as opposed to the surf scoter, which allows the completion of the life cycle.

Parasites cause a significant amount of deaths in marine animal populations. The Californian Department of Fish and Game approximated between 1,000 to 4,000 deaths of surf scoters due to an unusual high load of acanthocephalan parasites in 1995 [17]. In addition, $40 \%$ to $50 \%$ of the southern sea otters died from infectious diseases, of which 13-16\% have been linked to acanthocephalan peritonitis, the most prevalent one [18].

\section{Climate Effects on Transmission Between Hosts}

Sea surface temperatures play a major role in global weather, particularly in the marine ecosystem. The change in the normal sea temperature is a result of the accelerating climate change we are experiencing today, according to the El Niño-Southern Oscillation (ENSO) episodes classification table in Figure 4.

\begin{tabular}{|c|c|c|c|c|c|c|}
\hline \multicolumn{5}{|c|}{ El Niño } & \multicolumn{2}{c|}{ La Niña } \\
\hline Weak & Mod & Strong & Very Strong & Weak & Mod & Strong \\
\hline $1951-52$ & $1963-64$ & $1957-58$ & $1982-83$ & $1950-51$ & $1955-56$ & $1973-74$ \\
$1952-53$ & $1986-87$ & $1965-66$ & $1997-98$ & $1954-55$ & $1970-71$ & $1975-76$ \\
$1953-54$ & $1987-88$ & $1972-73$ & $2015-16$ & $1964-65$ & $1998-99$ & $1988-89$ \\
$1958-59$ & $1991-92$ & & & $1967-68$ & $1999-00$ & \\
$1968-69$ & $2002-03$ & & & $1971-72$ & $2007-08$ & \\
$1969-70$ & $2009-10$ & & & $1974-75$ & $2010-11$ & \\
$1976-77$ & & & & $1983-84$ & & \\
$1977-78$ & & & & $1984-85$ & & \\
$1979-80$ & & & & $1995-96$ & & \\
$1994-95$ & & & & $2000-01$ & & \\
$2004-05$ & & & & $2011-12$ & & \\
$2006-07$ & & & & $2016-17$ & & \\
& & & & & & \\
\hline
\end{tabular}

Figure 4: An overview of the years of EN and LN episodes since 1950 [16]

El Niño (EN) and La Niña (LN) are complex weather patterns resulting from 
variations in ocean temperatures in the Equatorial Pacific. They are opposite phases of the El Niño-Southern Oscillation cycle. These ENSO episodes often lead to extreme weather, which may impact a large number of ecosystems. El Niño is described as warmer-than-normal sea surface temperatures [29] in the central and eastern Pacific Ocean, near the equator off the west coast of South America. La Niña, its counterpart, is characterized by the sea temperature below the normal in the same area [29]. During a strong El Niño, sea temperatures increase on the average by $2^{\circ} \mathrm{C}$ to $3.5^{\circ} \mathrm{C}\left(4^{\circ} \mathrm{F}-6^{\circ} \mathrm{F}\right)$. Similarly, the sea normal temperatures decrease on average by $1^{\circ} \mathrm{C}-3^{\circ} \mathrm{C}\left(2^{\circ} \mathrm{F}-6^{\circ} \mathrm{F}\right)$ (Figure 5). ENSO episodes are approximately 9-12 months long. Currently, they start to form during June-August, reach their peak strength during December-April, and then decay during May-July of the following year. However, a few episodes have be prolonged to 2 years and even 3 to 4 years. While their periodicity can be quite irregular, EN and LN often occur every 3 to 5 years on average [29].

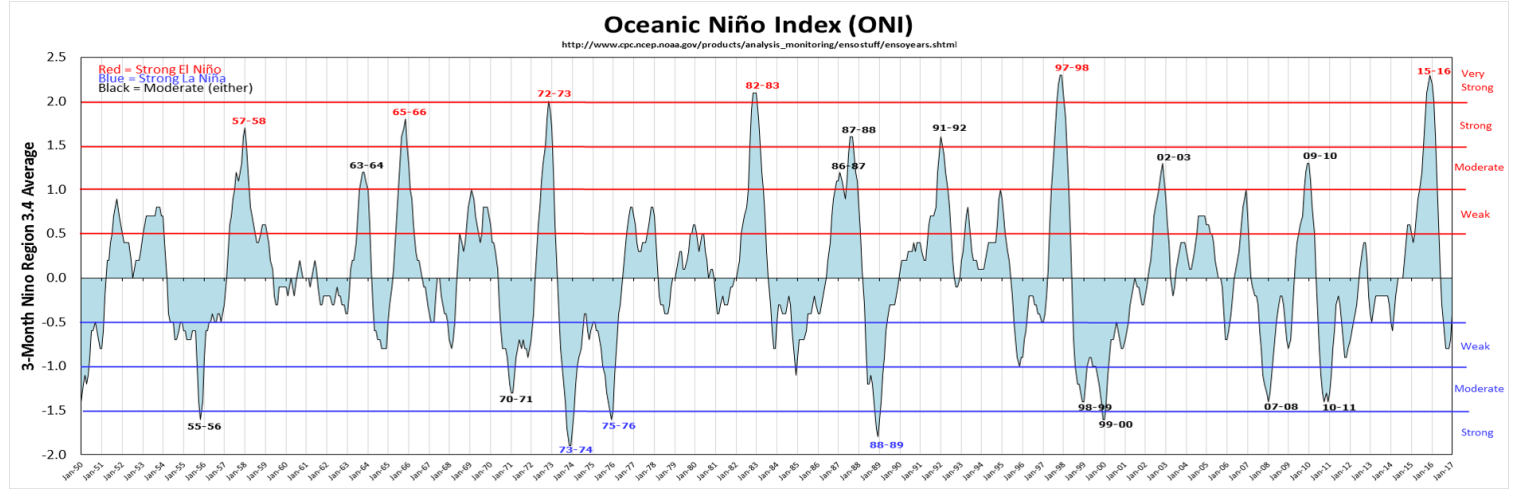

Figure 5: ENSO episodes with their intensity and the duration since 1950 [16]

Studies [30, 31, 32, 33] have shown that a change in ambient temperature of the sea water impacts marine biodiversity. In fact, sea temperature change may influence the performance of individual organisms, the distribution and behavior of species populations, 
their biological reproduction, and their dynamic and abundance. Oliva et al. showed that ENSO cycles have large impacts on the ecology [34]. Fiedler showed that by altering winds, rainfall, thermocline depth, and circulation patterns, EN and LN strongly impact the productivity, feeding, and reproduction of crustaceans, as well as birds and marine mammals [35]. In their 2002 paper, Mouritsen and Poulin also highlighted the fact that despite the evidence that the composition and structure of natural communities can be influenced by parasites, weather conditions often strongly impact parasite transmission. Thus, any perturbation in ecosystems that affects the structure of the food web will influence the transmission and abundance of the parasite [37].

During El Niño years, there is an increase of the abundance of sand crab populations [38]. Tokeson and Holmes found that a change in the temperature will significantly impact the acanthocephalan life cycle, most particularly at the cystacanth stage [39]. When temperature rises, the development of the eggs to the cystacanth stage occurs faster, increasing the abundance of acanthocephalan parasites and the prevalence of infection.

Understanding the impact of phenomena such as climate change, habitat loss, change in predator-prey community, and parasite transmission could be the key to preserving the marine ecosystem. The question of whether intermediate hosts of acanthocephalan parasites are strongly and directly affected by EN has been discussed [34]. In fact, Oliva et al. (2007) have suggested that the changes in the parasite population do not represent a direct consequence of EN, rather, EN events may initiate a cascade effect resulting in a significant decrease in the abundance of marine birds that act as definitive hosts for Profilicollis altmani, an acanthocephalan species. In their study, they found a significant difference in infection rates of mole crabs during EN events. Consequently, the abundance of sea birds decreases significantly during EN episodes, because the crabs are their food source. 


\section{Question Under Investigation}

The main question in this research is to determine whether EN episodes strongly impact the abundance of surf scoter populations along the Californian coast. We predict an increase in the prevalence of infected crabs during EN episodes. Since studies have shown that during EN birds spend more time on the coast (in contact with the crabs), we expect a decrease in their abundance as a consequence, because the acanthocephalan parasites are directly transmittable from sand crabs. Will a mathematical model help us demonstrate that the difference in temperatures has a significant impact on the size of the host populations? Before answering this main question, is it true that temperatures in $\mathrm{El}$ Niño and La Niña years are significantly different to produce different outcomes? If yes, is there any relationship (or correlation) between EN/LN temperatures and the prevalence of infected crabs from data observed at the Californian coast? Answers of these questions will help us support or revise our hypothesis. 


\section{CHAPTER II}

\section{MODEL DEVELOPMENT}

\section{Models}

Peritonitis is a disease caused by acanthocephalan parasites that kill marine animals such as surf scoters and sea otters through consumption of infected mole crabs. By developing a mathematical model that includes temperature-dependent parameters, we can analyze the influence that El Niño events have on the prevalence of infected sand crabs and seabird mortality.

\section{Model Parameters}

In our model, we assumed parameter values either from existing literature or studies based on similar biological systems. The parameters $\chi$ and $k_{c}$ are found by parameter estimation methods using a data from Long-term Monitoring Program and Experiential Training for Students (LiMPETS) website. LiMPETS data was collected from 2002 to 2016 by students from various schools. Participants reported the number of sand crabs as well as the number of parasites found inside each crab along 29 different sites in California coast [40].

We summarized the parameters of the model in Table 1. 
Table 1: Summary of species parameters, their biological meaning, and the source

\begin{tabular}{llll}
\hline \hline Parameter & Biological Meaning & Mean Value & Source \\
\hline$\Lambda_{\text {in }}$ & Bird in-migration number per day & 80.0 & {$[2]$} \\
$\Lambda_{\text {out }}$ & Bird out-migration rate per day & $1 / 21$ & {$[2]$} \\
$\beta$ & Bird infection rate per day & 0.1 & {$[94]$} \\
$\mu_{b}$ & Bird natural death rate per day & $1 /(9.5 * 365.25)$ & {$[1]$} \\
$k_{b}$ & Bird infection mortality per day & 0.034 & {$[90]$} \\
$r_{c}$ & Crab natural growth rate at low density & 0.15 & {$[91,92]$} \\
$K_{c}$ & Crab carrying capacity & 17,500 & {$[89]$} \\
$\gamma$ & Parasite development from egg to juvenile & temp. dependent function & {$[39]$} \\
$\chi$ & Crab probability of getting infected & $0.07 / 200$ & {$[40]$} \\
$\mu_{c}$ & Crab natural death rate per day & $1 /(2.5 * 365.25)$ & {$[89]$} \\
$k_{c}$ & Crab infection mortality & 0.006 & {$[40]$} \\
$r_{o}$ & Otter natural growth rate at low density & 0.10 & {$[12]$} \\
$K_{o}$ & Otter carrying capacity & 16,000 & {$[88]$} \\
$\rho$ & Otter probability of getting infected & 0.008 & {$[95]$} \\
$\mu_{o}$ & Otter natural death rate per day & $1 /(23 * 365.25)$ & {$[1]$} \\
$k_{o}$ & Otter infection mortality rate per day & 0.25 &
\end{tabular}

\section{Differential Equation Model Development}

We used a compartmental model where we assumed that crabs will continue to host the cystacanth form of the parasite and that infected birds will migrate out of the area, so neither host will have a recovery stage. 


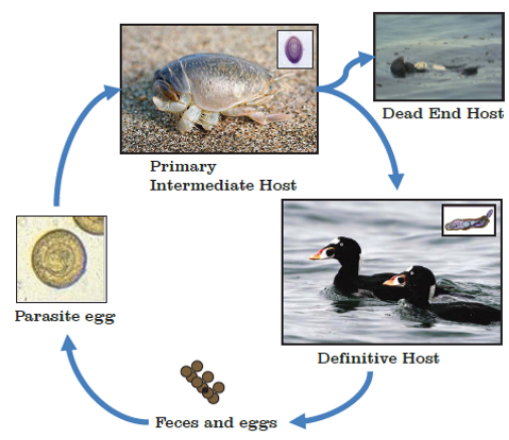

(a) Acanthocephala life cycle

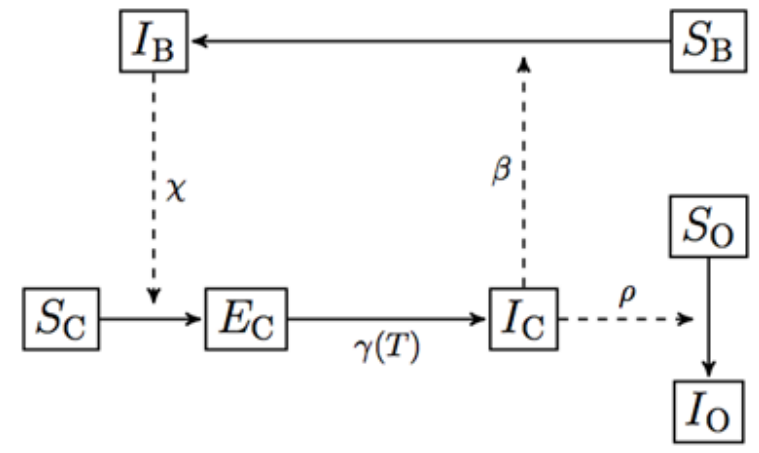

(b) Acanthocephala transmission map

Figure 6: Acanthocephala life cycle and the transmission map derived from it

Figure 6 show the parasite cycle and the model transmission map to help visualize the different stages and the parameters involved in each stage of the parasite transmission.

\section{Susceptible and Infected Surf Scoters}

We categorize surf scoter populations as either susceptible $\left(S_{b}\right)$ or infected $\left(I_{b}\right)$. We assume that:

- The number of susceptible birds increases through recruitment of uninfected surf scoters (either by birth or immigration) at an in-migration rate of $\Lambda_{i n}$ birds per day, and decrease when susceptible birds migrate out at an out-migration rate of $\Lambda_{\text {out }}$ per day, or by natural death at a rate of $\mu_{b}$ per day. New migrants are all uninfected, given the rapid mortality of infected birds.

- The population of infected birds is reduced by natural death or by death due to infection, which occurs when a susceptible bird ingests an infected crab, at a rate of $k_{b}$ per day.

- Transmission of the parasite from crab to bird occurs when the bird consumes an infectious crab. The number of crabs eaten by a susceptible bird is assumed to be 
frequency-dependent. The number of interactions is:

$$
S_{b}\left(\frac{I_{c}}{S_{c}+E_{c}+I_{c}}\right) .
$$

The number of new infections caused by parasite transmission from acanthocephalans to surf scoters per day is the number of interactions times the probability, $\beta$, that an infectious crab produces a new infection in a susceptible bird.

Thus, the rates of change in the susceptible and infected bird populations are:

$$
\begin{aligned}
& \frac{d S_{b}}{d t}=\Lambda_{\text {in }}(t)-\Lambda_{\text {out }}(t) S_{b}-\mu_{b} S_{b}-\beta S_{b}\left(\frac{I_{c}}{S_{c}+E_{c}+I_{c}}\right) \\
& \frac{d I_{b}}{d t}=\beta S_{b}\left(\frac{I_{c}}{S_{c}+E_{c}+I_{c}}\right)-\mu_{b} I_{b}-k_{b} I_{b}
\end{aligned}
$$

\section{Susceptible and Infected Mole Crabs}

Following the development of the parasite from egg to juvenile stage, we divide sand crab populations into three categories. Let

$S_{c}(t)=$ number of susceptible crabs,

$E_{c}(t)=$ number of exposed crabs (infected), but not infectious, and

$I_{c}(t)=$ number of infectious crabs.

We assume that:

- In the absence of the disease, susceptible crabs follow a logistic growth model towards the environmental carrying capacity, $K_{c}$, at a natural growth rate (at low density) of $r_{c}$ :

$$
r_{c} S_{c}\left(1-\frac{S_{c}}{K_{c}}\right) .
$$


- In this case, unlike the transmission from infected crab to susceptible bird, we assume that transmission from infected bird to susceptible crab is density-dependent. Crabs are removed from the susceptible group through infection and natural death. The probability for each susceptible crab to be infected via infected bird feces is $\chi$.

- An exposed crab is a crab that is infected without being infectious yet because of the delay in the juvenile stage of the parasite. The population $E_{c}$ represents exposed crabs initially infected by acanthocephalan eggs released with the feces of infected birds $\left(I_{b}\right)$. An infected crab becomes infectious only after the development time of a parasite from egg to juvenile. We define $\gamma(T)$, a temperature-dependent function, as the rate of development from egg to juvenile stage of the acanthocephalan parasite within an infected crab.

- Infected crabs is the number of crabs that are infectious. In other words, they represent the completion of the first stage of parasite cycle (from egg to juvenile). Once infectious, the crab becomes more exposed (due to the parasite's adaptive manipulation) to predators and therefore can transmit the disease to a susceptible definitive host. A crab in this state can be lost from the population through natural death (which includes predation) at the rate of $\mu_{c}$ per day, or through death due to infection at the rate of $k_{c}$ per day.

The rates of change in the crab subpopulations are described as follows:

$$
\begin{aligned}
& \frac{d S_{c}}{d t}=r_{c} S_{c}\left(1-\frac{S_{c}}{K_{c}}\right)-\chi S_{c} I_{b} \\
& \frac{d E_{c}}{d t}=\chi S_{c} I_{b}-\gamma(T(t)) E_{c} \\
& \frac{d I_{c}}{d t}=\gamma(T(t)) E_{c}-\mu_{c} I_{c}-k_{c} I_{c} .
\end{aligned}
$$




\section{Susceptible and Infected Sea Otters}

Just like the bird populations, we separate sea otters into two categories, susceptible $\left(S_{o}\right)$ or infected $\left(I_{o}\right)$ :

$S_{o}(t)=$ number of susceptible otters, and

$I_{o}(t)=$ number of infected otters.

- In the absence of the disease, susceptible sea otters (which commonly reside year-round on California beaches) follow a logistic growth model towards the environmental carrying capacity, $K_{o}$, at a natural growth rate (at low density) of $r_{o}$ :

$$
r_{o} S_{o}\left(1-\frac{S_{o}}{K_{o}}\right) .
$$

- The susceptible sea otters $S_{o}$ leave the population after being infected by infectious crabs. Parasite infection occurs when a susceptible sea otter consumes an infectious crab. The number of infected crabs eaten by a susceptible sea otter is also assumed to be frequency-dependent:

$$
S_{o}\left(\frac{I_{c}}{S_{c}+E_{c}+I_{c}}\right) \text {. }
$$

Thus, the number of new infections caused by parasite transmission from Acanthocephala to sea otters per day is the number of contacts times the probability, $\rho$, that an eaten infectious crab produces a new infection in a susceptible sea otter.

- Sea otters are removed from the infected group through infection mortality at a rate of $k_{o}$ per day or through natural death at a rate of $\mu_{o}$ per day. Note that sea otters are a dead-end host species, therefore, the parasite cannot complete its life cycle in a sea otter. 
The rates of change in the susceptible and infected sea otter populations are given by the following system of differential equations:

$$
\begin{aligned}
& \frac{d S_{o}}{d t}=r_{o} S_{o}\left(1-\frac{S_{o}}{K_{o}}\right)-\rho S_{o}\left(\frac{I_{c}}{S_{c}+E_{c}+I_{c}}\right) \\
& \frac{d I_{o}}{d t}=\rho S_{o}\left(\frac{I_{c}}{S_{c}+E_{c}+I_{c}}\right)-\mu_{o} I_{o}-k_{o} I_{o} .
\end{aligned}
$$

\section{Temperature Dependence}

Temperature is among the most important factors in climate patterns. It influences the weather and affects the life cycles of living species. A small variation in temperature can have a powerful impact on the environment worldwide. In our study, we examine the role of climate oscillation due to El Niño and La Niña on abundances of infected hosts.

During winter, surf scoters immigrate to the Central Coast until the spring season, when they migrate back to Canada or Northern Alaska for nesting. In general, the spring migration starts in March, while the fall migration begins at the end of October [42]. Thus, in April, it is very common to see a gradual increase in the surf scoter flocks floating on the coast as the month passes, because they stop over a few days for food and rest during the nesting migration. With a change in the weather, the flocks decrease or just migrate out toward the north [43]. According to De La Cruz et al. [44], there is evidence that the duration of the spring migration, as well as the quality and quantity of foods accumulated during a stopover, can positively impact the success of female reproduction and survival, particularly for species nesting on the arctic coasts [49, 50, 51]. Also, some studies [2] show that some migratory birds change their migration strategies to optimize their fitness (by reducing the migration timing, increasing the amount of energy from the stopover sites, or simply by avoiding predators) $[45,46,47,48]$. This explains why surf scoters tend to shift sites for food during late winter and spring migrations to benefit from the 
seasonal foods (e.g., crabs and herring spawn) [2]. Hence, understanding the migration ecology may be very powerful in predicting the abundance of seabirds during a change in the temperature, especially for the surf scoter populations at the California coast, where food availability is expected to change drastically with climate change $[53,54]$. Such information can be useful in protecting the surf scoter species in particular and many other migratory birds in general [44].

Like all marine animals, sand crabs are known to be very sensitive to ocean temperatures. Warmer sea temperatures affect the life cycle of marine animals and plants. In fact, a small increase in the sea temperature can led to a shift in species distribution and behaviors, and therefore can affect the biodiversity of the ecosystem. A study conducted by the Farallones Marine Sanctuary Association suggested that sand crab abundance on the coast is influenced by all factors of the environment including temperature [55]. Thus, crab populations may thrive when the temperature increases. According to the above study, a much larger proportion of female crabs produce eggs in warmer water than in cold, and eggs are produced more rapidly in warm water than in cold. Egg development time is considerably shortened by warm water and as a result, the crab population increases. Sand crabs are a common food source for many animals including surf scoters and sea otters on California beaches and they are also known to carry parasites such as Acanthocephala. Hence, the probability of crabs getting infected from parasite eggs will increase, causing more infectious crabs at risk of predation.

The accurate prediction of the expansion of parasites and their hosts can be very important in the prevention of epidemic diseases, therefore, parasitology is one of the most sensitive topics related to global change effects [56]. Furthermore, numerous studies suggest that parasitism is influenced by climate change [57, 58, 59]. Among the components of climate, temperature plays an important role in the parasite growth, reproductive development, and life cycle completion rates [60]. This may affect the 
defense system of the hosts, the parasite virulence, and its capacity of transmission. Moreover, warmer sea temperatures have been linked to the increase in invasive species populations and the prevalence of marine diseases. When an ecosystem becomes warmer, there is a chance for some invasive parasites to thrive and therefore disturb or simply jeopardize the well-being of native species [61]. Other studies suggest that parasite development time in its intermediate host could alter the intensity of their behaviors [62, 63]. Tokeson and Holmes (1982) showed that the time for acanthocephalan parasites to develop is greatly affected by temperature, which can indirectly increase the intensity and the duration of the manipulation [39].

In our model, only temperature is assumed to affect the development time of the parasites from egg to juvenile. We included the seasonality of the birds as time-dependent functions because we are considering immigration and emigration of birds over a year, and therefore we assumed that they are not directly related to temperature. However, most surf scoters migrate during the spring, at the beginning of March [42], which corresponds to the period when the temperature gets warmer. The fall migration begins mid-to-late October [42], when the temperature gets colder; therefore, the migration seasons could also be temperature-dependent. Since birds can be sensitive to temperature, there is enough evidence that migration seasons, which we assumed are time-dependent, may rather be temperature-dependent.

We defined the rate of development, $\gamma$, from egg to juvenile stage of the Acanthocephala within an infected crab. Using the linear relationship to temperature found in Tokeson and Holmes (1982) [39], we defined the rate of development to the cystacanth stage, $\gamma$, as a function of $\mathrm{T}$ (temperature of the sea-surface measured in Celsius):

$$
\gamma(T)=\frac{1}{100}(0.216 * T-2.002) .
$$


As we are interested in the effect of temperature on the spread of the disease and the abundance of surf scoters, we first related the temperature to our primary independent variable time, $t$ (in days). By interpolation, we found a relationship between temperature and time using monthly water temperature data (in degrees Celsius) obtained from the National Oceanic and Atmospheric Administration (NOAA) [29]. Thus, with this interpolation function, we can estimate the temperature of any day.

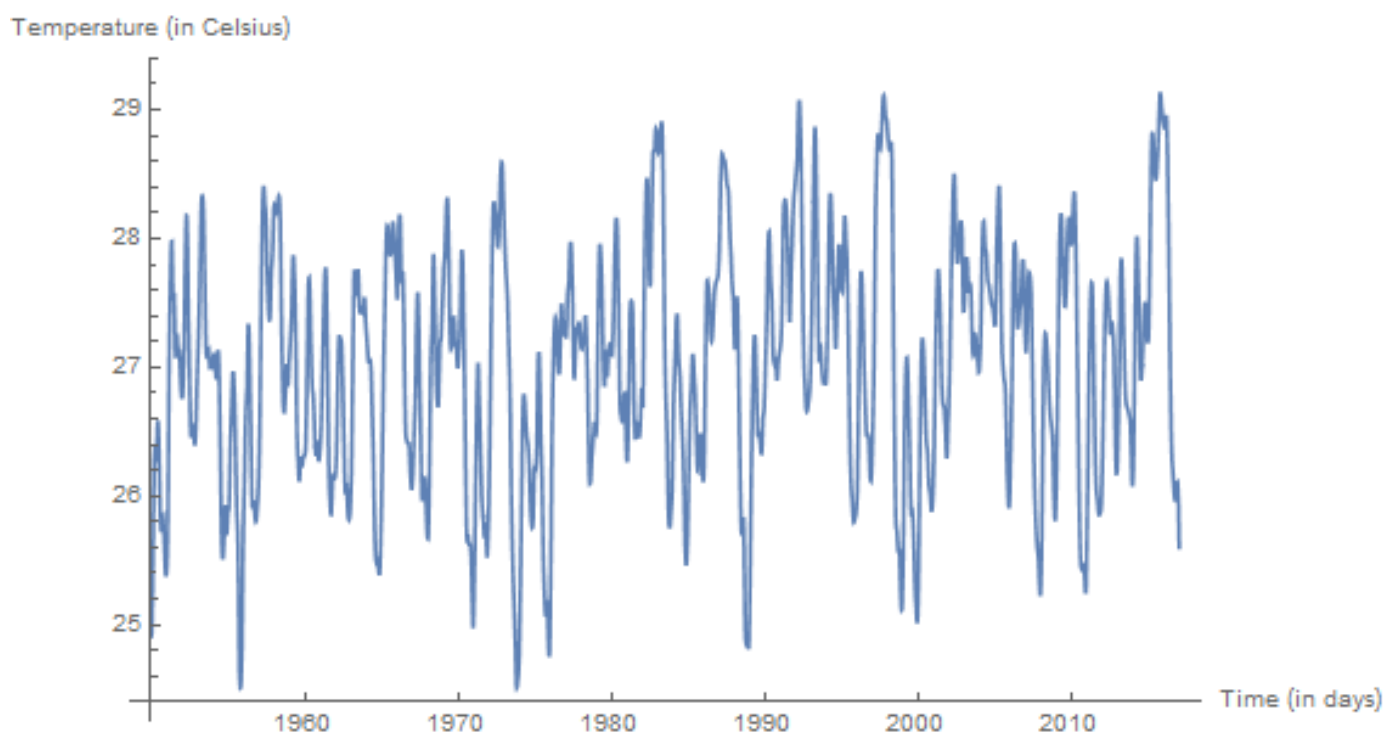

Figure 7: Temperature as a function of time from January 1950 to January 2017

With the function $\gamma(T)$, we are able to approximate the development rate of infectious crabs at any time. As an example, Figure 7 shows the exposure rate of infectious crabs from January 1950 to December 1960. 


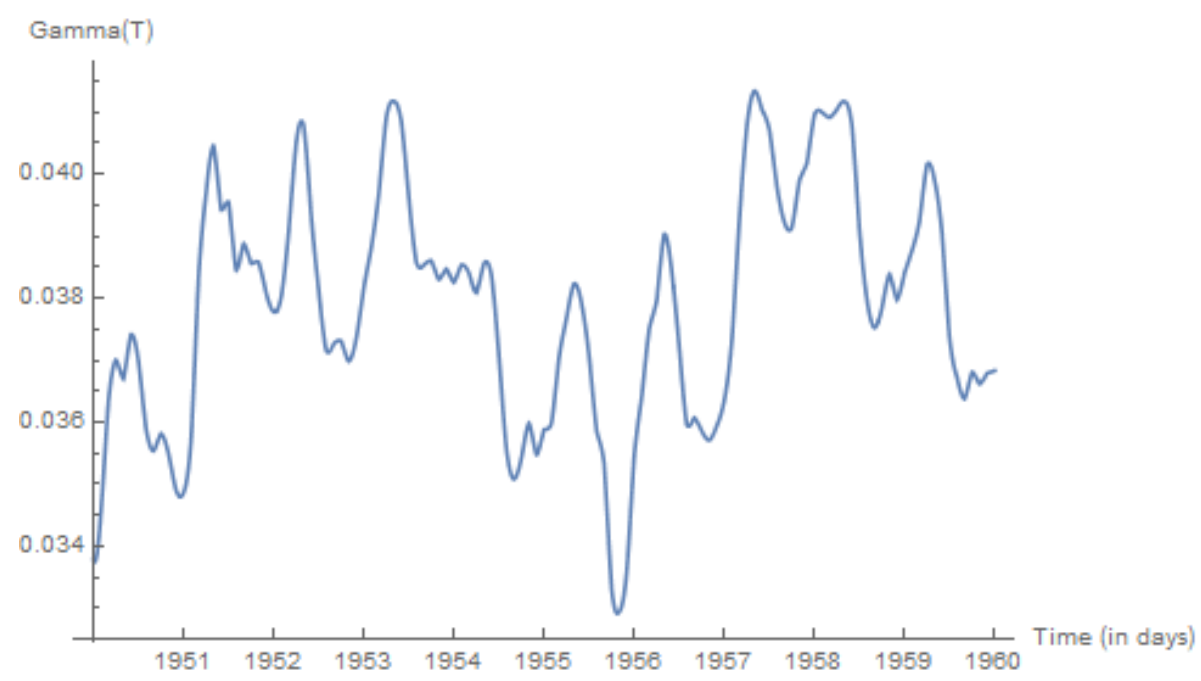

Figure 8: Graph representing the function $\gamma(T)$ over 10 years

\section{EN and LN Differences}

El Niño and La Niña are caused by the temperatures of the sea surface in the tropical zone of the Pacific Ocean interacting with the atmosphere. El Niño is described as warmer-than-normal sea surface temperatures in the central and eastern Pacific Ocean, near the equator off the west coast of South America [29]. During El-Niño, sea temperatures rise on the average between $1{ }^{\circ} \mathrm{C}$ to $3.5^{\circ} \mathrm{C}$ [64]. La Niña is El Niño's complete opposite [29]. It is described as cooler-than-normal sea surface temperatures in the same area of the Pacific Ocean with a decrease on the average by $1^{\circ} \mathrm{C}-3^{\circ} \mathrm{C}$ [64]. In the development of our mathematical model, we used temperature data from January 1950 to January 2017 provided by the National Oceanic and Atmospheric Administration [29]. We split the data into two categories: EN years and LN years. Within each category, we also have two subcategories: weak and strong.

\section{Model Analysis}

Mathematical models are used to approximate numerous highly complex systems in engineering, physics, biology, chemistry, and economics. To build a model, 
assumptions and parameters are very important and are subject to change and error measurement. Equations modeling a spread of disease depend on several parameters. Thus, assigning values to parameters is very important, as poor values lead to poor results and therefore could be misleading in the analysis of solutions. Parameter values are either estimated or approximated from previous studies. In the model development, one of most important steps is to parametrize the model and also determine which parameters are most influential on the results. Sensitivity analysis (SA) is the study of how the uncertainty or variability in the parameters can contribute to the overall output result [69]. According to Baird, SA is also used to investigate potential changes and errors of a parameter and how they impact the model conclusions [66]. It is a very useful method for model validation as well as a guide for future research efforts. Pannell (1997) suggested that sensitivity and stability analysis should be included integrally in any solution methodology because they are important in understanding the status of a solution [65]. In addition to providing information about how a model is sensitive to a parameter, SA also tells us the amplitude of that sensitivity. Therefore, it is essential to differentiate parameter sensitivity from parameter importance. According to Hamby (1994) [69], a parameter is important to a model if any change in it leads to considerable variability in the model; therefore, it is sensitive. But a model can be sensitive to a parameter and still have little variability. In summary, importance implies sensitivity but the converse is not true.

There are different approaches $[69,76]$ to performing SA in a model. In our paper, we use the simplest approach consisting of the change of one factor at a time, called One Factor At a Time (OFAT) [76]. OFAT consists of varying one input variable (or parameter) by a certain percentage, while keeping others the same as the base case, and observing the sensitivity index. We repeat this process for each parameter of interest in the same way. The base case of a SA is defined as the result of the output when all parameters are held constant and equal to base values. A sensitivity index (SI) or sensitivity 
coefficient can be defined as the ratio of the variation in output to the variation in input as each parameter increases [72]. According to Hoffman and Gardner (1983) and Bauer and Hamby (1991), the simplest approach to investigate parameter sensitivity is to evaluate the percentage of outcomes difference when a single parameter varies in a range of values between its minimum value and its maximum value [70, 71]. To evaluate the true sensitivity of a parameter, Hoffman and Gardner (1983) suggest using the entire range of possible values of each parameter [70]. Thus, they define the sensitivity index (SI) as

$$
S I=\frac{D_{\max }-D_{\min }}{D_{\max }}
$$

where $D_{\max }$ and $D_{\min }$ are the outcomes when the parameter is equal to its maximum and minimum values, respectively.

In this paper, we are only interested in the ratio of the variation of the output from the base case for each parameter, therefore we defined the sensitivity index as

$$
S I=\frac{D_{r}-D_{i}}{D_{i}}
$$

where $D_{i}$ is the base case and $D_{r}$ is the output result when a parameter increases by $r \%$.

Since the abundance of surf birds is our main concern, we decided to set our base case equal to the yearly average number of infected birds over 10 years $\left(D_{i}\right)$. We increase each parameter by $10 \%$ (the common percentage used) and run the model each time to find the new yearly average number of infected birds $\left(D_{10}\right)$. We then calculate the corresponding SI.

Here is the summary of the SI for the parameters involved in the model: 
Table 2: Summary of the sensitivity index for the model parameters

\begin{tabular}{ccccccccc}
\hline \hline Percent & $S I_{\beta}$ & $S I_{\chi}$ & $S I_{k_{b}}$ & $S I_{k_{c}}$ & $S I_{r_{c}}$ & $S_{\rho}$ & $S I_{r_{o}}$ & $S I_{k_{o}}$ \\
\hline $10 \%$ & 0.001 & -0.001 & -0.09 & -0.001 & 0.001 & 0 & 0 & 0 \\
\hline
\end{tabular}

According to Table 2, the yearly average number of infected birds is very sensitive to parameters related only to bird and crab populations. On the other hand, any change in parameters related to sea otters has no effect on that output. This result matched up with our expectation because parameters related to sea otters are not necessary parts of the life cycle of acanthocephalan parasite (because the sea otter, as we recall, is a dead-end for the parasite).

The SI of the parameters $\beta$ and $r_{c}$ are positive and thus they increase the yearly average number of infected birds. By contrast, the parameters $\chi, k_{b}$, and $k_{c}$ give a negative SI value, which tells us that they decrease the number of infection in bird populations. Moreover, the absolute value of SI is higher in $k_{b}$ than in any other parameter in the model. This sensitivity analysis demonstrates that the number of infected birds due to acanthocephalan parasites is more 'sensitive' to changes in the bird infection death rate $\left(k_{b}\right)$ than in the crab natural growth rate at low density $\left(r_{c}\right)$, the crabs' contact rate with feces containing acanthocephalan parasite eggs $(\chi)$, the infection between birds and infected crabs $(\beta)$, and the death due to infection in crab populations $\left(k_{c}\right)$. Another important fact is that SA encourages us to use real data, like the data from LiMPETS, to estimate accurately the values of $\chi$ and $k_{c}$.

The second part of our model analysis is the study of the stability of the solutions of the differential equations system. As we mentioned earlier in this paper, some parameters are time or temperature-dependent. Consequently, climatic events (ENSO episodes) and seasonal variations (e.g., bird migration and crab abundance) influence significantly the 
spread of acanthocephalan parasites. Since the temperature input is a nearly-periodic function (see Figure 7), the solutions of our model may also become periodic. We used Floquet theory (FT) to test the stability of periodic solutions of our nonlinear model. FT is used in modeling biological, ecological, and evolutionary problems [78]. This mathematical tool is very useful in studying non-equilibrium dynamics to understand the temporal variability of periodic systems [73]. In fact, model diversity is found to be complex because it can either be increased [97, 77, 98] or decreased [99] by fluctuations that make non-equilibrium dynamics hard to analyze. Using Mathematica code provided by Klausmeier (2008), we determinined the stability of a periodic orbit, which is a solution to the temporal dynamical system [73]. Similar to the stability of the fixed point of a Poincaré map (using eigenvalues) [76], the stability of the periodic orbit is determined based on the Floquet exponents or Floquet multipliers. Thus, Floquet exponents can be interpreted in the same way as eigenvalues in models with constant coefficients: they represent the variation of the different perturbations over a cycle and have a unit of per

time $\left(\right.$ time $\left.^{-1}\right)$. The periodic orbit is stable if all Floquet exponents have negative real parts or have real parts between -1 and 1 ; otherwise it is unstable [69].

\section{Initial Conditions}

We start the model at $\mathrm{t}=0$, corresponding to January 1st. At this time, we will assume that the number of scoters is relatively close to 1,000, with approximately 100 infected birds due to acanthocephalan parasites. Also, we will assume that the susceptible, infected, and exposed crab populations are 1,700, 100, and 0 respectively. Finally, we will assume that on January 1st, there are 160 sea otters, none of them being infected yet.

For our model, we modified the Mathematica code created by Klausmeier (2008) [73] to numerically approximate the Floquet exponents. With a system of seven differential equations, the Floquet exponents are given by the vector display $\left(-0.0002,-0.0002,7.5 \cdot 10^{-19}, 4.44 \cdot 10^{-17}, 2.31 \cdot 10^{-13}, 0.0724,0.2747\right)$. 
The largest exponent is 0.2747 , so its absolute value is less than 1 . Thus, we conclude that our model has a stable periodic cycle. 


\section{CHAPTER III}

\section{APPLICATIONS}

After we create a mathematical model with a system of differential equations that relate all hosts in the biological system with the temperature-dependent parasite development time, we parametrize our model and then investigate its stability using data from LiMPETS and NOAA, as well as what we learned from our sensitivity analysis (SA) and Floquet theory (FT). Finally, we want to show that EN impacts the prevalence of infected crabs, and relate that to bird population abundance.

\section{Data Description}

To determine estimates for the model parameters $\left(\chi\right.$ and $k_{c}$ ), we used data obtained from LiMPETS ([40]). LiMPETS data was collected by students from August 2002 to November 2016 on 29 different beaches along the Californian coast. Crabs were captured and placed in plastic bags, and those bags were placed in a freeze for more than 4 hours. The students then thawed and dissected the crabs to count the number of acanthocephalan parasites present in the midgut of each crab ([40]). In the datasheet, they recorded the date, the location, the school that collected the data, the total number of crabs, the prevalence (number of crabs with parasites), the total number of parasites, the percentage of crabs with parasites, the mean abundance (average number of parasites per crab), and the intensity (average number of parasites per crabs with parasites). Unfortunately, the data was not collected periodically, and the number of crabs collected per site is variable. Therefore, we decided to restrict the data obtained to the Ocean Beach site because it includes a greater number of observations $(n=110)$. We calculated and plotted the mean and the standard error of the percentage of infected crabs per month for an overall pattern. 


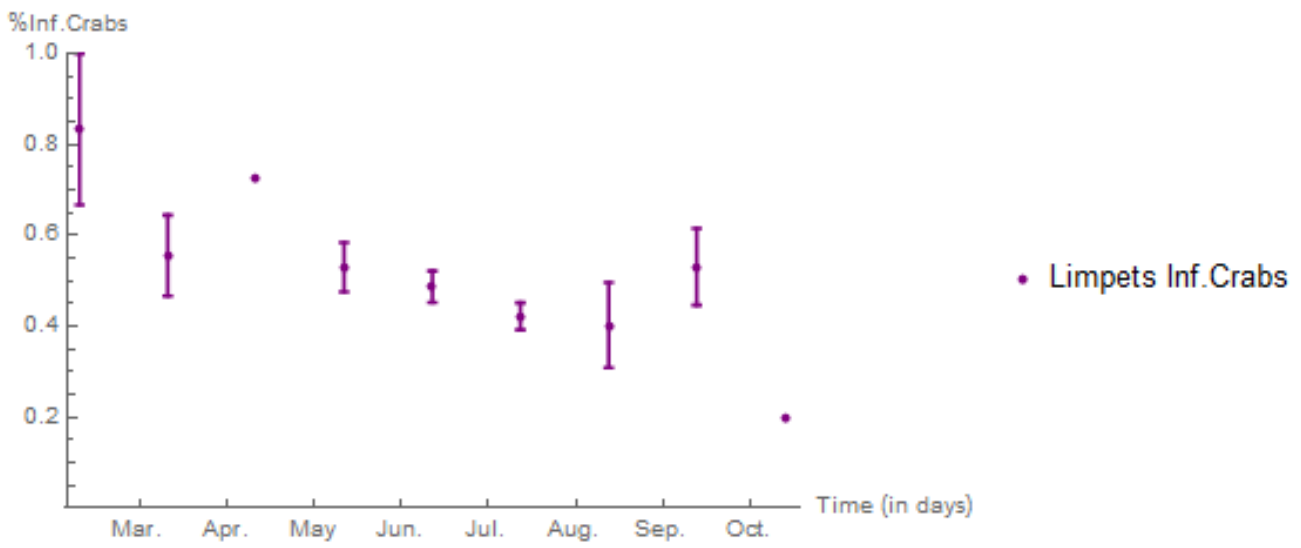

Figure 9: Mean and standard error of infected crabs prevalence (LiMPETS data)

During the birds residence time (previous fall) at the coast, parasites perpetually produce eggs and the likelihood of the crabs being exposed increase until birds leaves. Consequently, in spring, the percentage of infected crabs observed is higher. The birds migrate out from the coast but there is still a little residual carryover of eggs produced by infected birds before their departure. These eggs create new infections in crab population, therefore increase the prevalence of infected crabs. Once all eggs are removed from the water (eaten by crabs or destroyed), the percentage of infected crabs reach a maximum value above $80 \%$. With the removal caused by natural death or predation, the crab prevalence percentage decreases to almost $40 \%$. In the fall, the birds come back again and the prevalence of infected crabs starts going up (see Figure 9).

\section{EN-LN Significance T-Test}

Before we investigate EN impact on all hosts in our model, it is crucial to check whether the temperatures in EN and LN are significantly different. We divided the NOAA data (described earlier) into two categories, El Niño (EN) and La Niña (LN), with two subcategories, Weak (Wk) and Strong (Strg) in each of them (Table 4). Then, we computed the mean temperature of each category and subcategory to get an idea about 
their difference.

Table 3: EN and LN temperature differences

\begin{tabular}{ccc}
\hline \hline Statistic & El-Niño & La-Niña \\
\hline Mean & 27.53 & 26.23 \\
\hline
\end{tabular}

Table 4: Difference within and between EN and LN

\begin{tabular}{ccccc}
\hline \hline Parameter & Weak EN & Strong EN & Weak LN & Strong LN \\
\hline Mean & 27.37 & 28.01 & 26.23 & 25.50 \\
\hline
\end{tabular}

During EN, the mean temperature of weak episodes is smaller than the mean temperature of strong episodes (see Table 3). Conversely, the weak episodes have a higher mean temperature compared to the strong episodes, during LN. Also, we notice differences between strong EN and strong LN as well as between weak EN and weak LN (Table 4). Thus, we can conclude that temperatures between and within EN and LN have different mean values.

We now examine the specific cases of the regular year 1981, the EN year 1982, and the LN year 1984, which are close to each other. Using the interpolation function between temperature (in ${ }^{\circ} \mathrm{C}$ ) and time (in days), we plotted the graphs of these three years to show the difference in temperatures. 


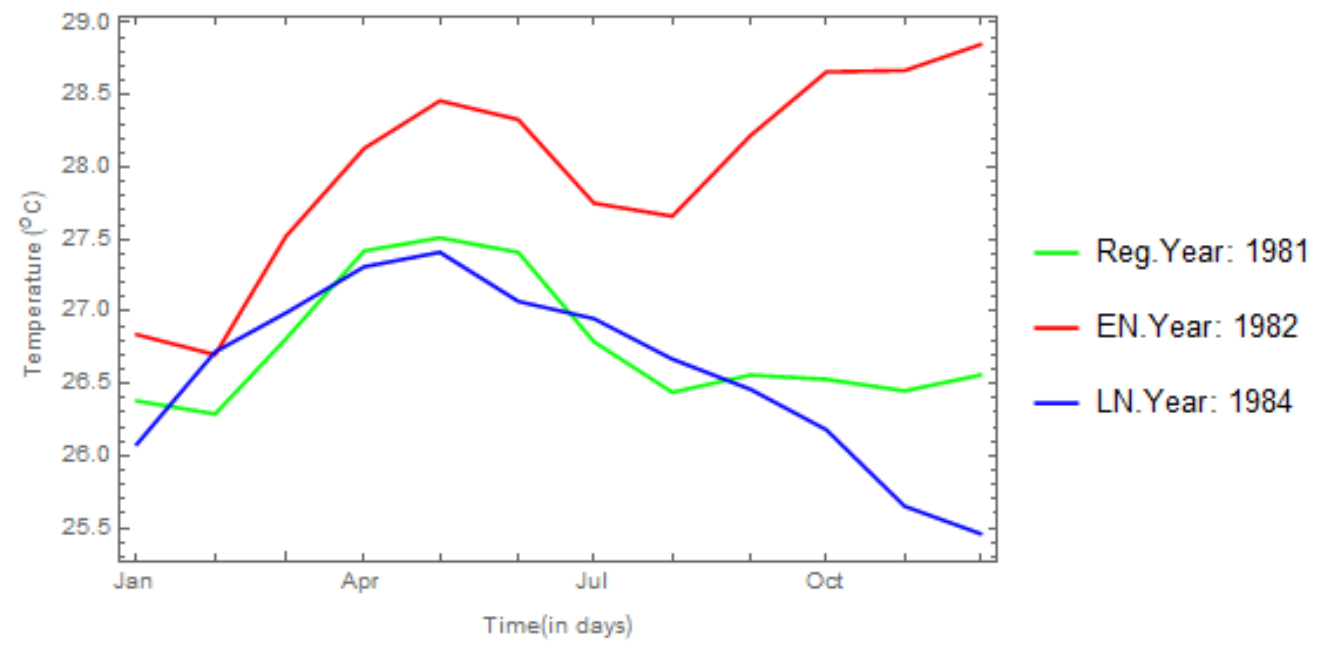

Figure 10: This figure compares the temperatures in 1981, 1982, and in 1984

In 1982 , the temperature mainly increases from $26.6^{\circ} \mathrm{C}$ in January to almost $30^{\circ} \mathrm{C}$ in December. During 1981, it increases from $26.4^{\circ} \mathrm{C}$ in February, reaches its peak at $27.6^{\circ} \mathrm{C}$ in April, and then decreases steadily up to August. On the other hand, in 1984, the temperature starts at $26.1^{\circ} \mathrm{C}$ in January, reaches its peak at $27.4^{\circ} \mathrm{C}$ in May, and then decreases to $25.4^{\circ} \mathrm{C}$ on December (Table 10). Thus, we conclude that EN and LN temperatures behave differently and could result in different impacts on hosts.

Now, to determine whether EN and LN temperatures are significantly different, we perform another statistical analysis (two-sample t-test) on the four subcategories defined above.

Our hypothesis for each test is as follows:

$H_{O}: \mu_{i}=\mu_{j}$

$H_{A}: \mu_{i} \neq \mu_{j}$; where $\mu_{i}$ and $\mu_{j}$ represent the temperature mean value for subcategories i and j, respectively.

Thus we obtained and sorted the probability value ( $p$-value) for each of the four t-tests. 
Table 5: Summary of the two-sample t-test

\begin{tabular}{ccccc}
\hline \hline Stat. & WkEN vs StrgEN & WkLN vs StrgLN & StrgEN vs StrgLN & WkEN vs WkLN \\
\hline p-value & $2.14 \cdot 10^{-3}$ & $6.39 \cdot 10^{-7}$ & $2.65 \cdot 10^{-10}$ & $8.96 \cdot 10^{-6}$ \\
\hline
\end{tabular}

At a significant level $\alpha$, if the probability value (p-value) of a two-sided test is less than or equal to $\alpha / 2$, then we reject the null hypothesis $\left(H_{O}\right)$. Let consider a $5 \%$ level of significance. Each p-value obtained (Table 5) is less than 0.25, therefore at 5\% level of confidence, we reject the null hypothesis. Thus, all of these four subcategories are statistically different from each other. The significance tells us that EN and LN may impact the number of species in our model differently. Now, we can investigate the impact of $\mathrm{EN} / \mathrm{LN}$ on the prevalence of infected crabs.

\section{Implementation}

Using the parameter values defined in Table 1, we plotted the number of susceptible and infected birds obtained from our simulation, on the same scale to see the change in those populations during the migration seasons. 


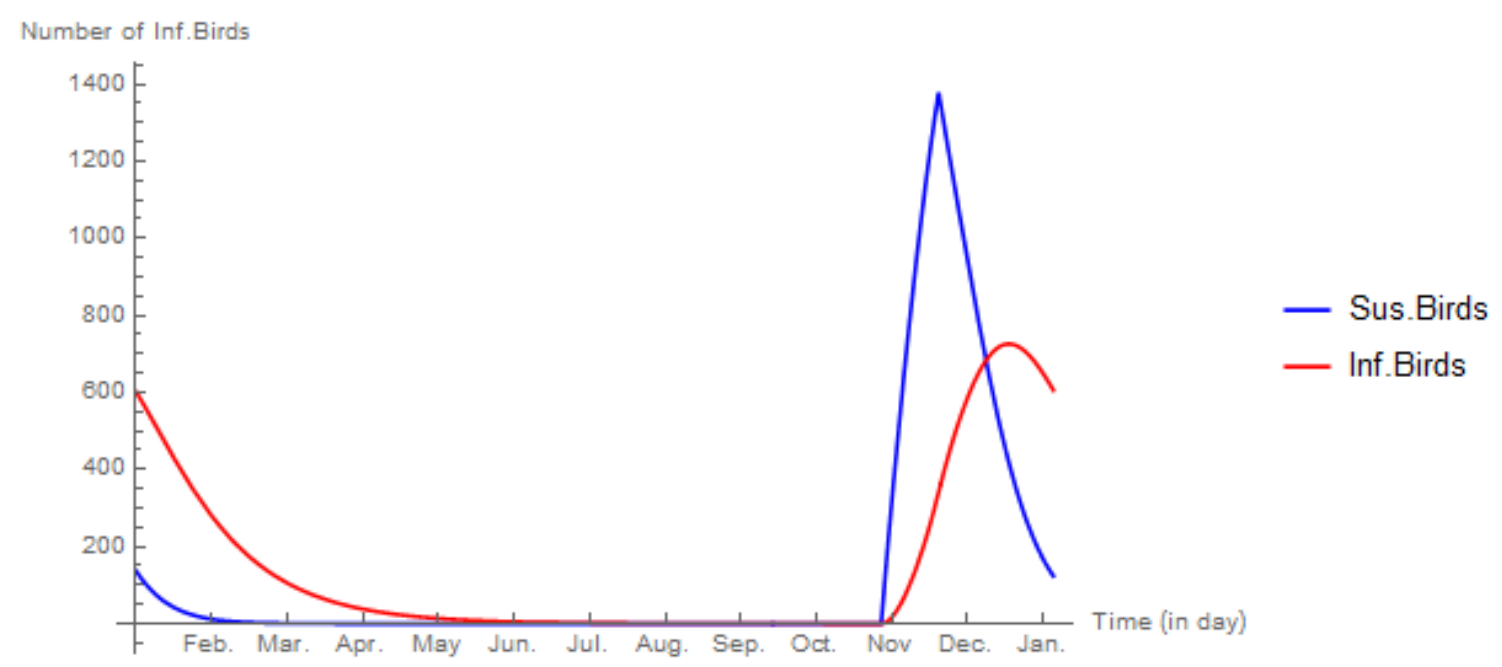

Figure 11: Number of susceptible and infected birds during migration season

The birds migrate to the coast in the fall, which increases the number of susceptible birds. Because infected crabs are already there, they become infected and, hence, the number of susceptible birds decreases. In the meantime, the number of infected birds increases until there are no new infections and then decreases (see Figure 11). At the beginning of spring, both the susceptible and infected populations decrease, as most birds migrate out, and some die (natural death or/and death due to infection). This is similar to what has been observed [42].

Since the LiMPETS data measured the percentage of infected crabs (observed) on Ocean Beach, we can assess the relevance of solutions (predicted by the model) to the model by comparing them. So, we plotted the mean with the standard errors from LiMPETS data and the percentage of susceptible, exposed, and infected crabs obtained on the same graph to compare the scenarios. 


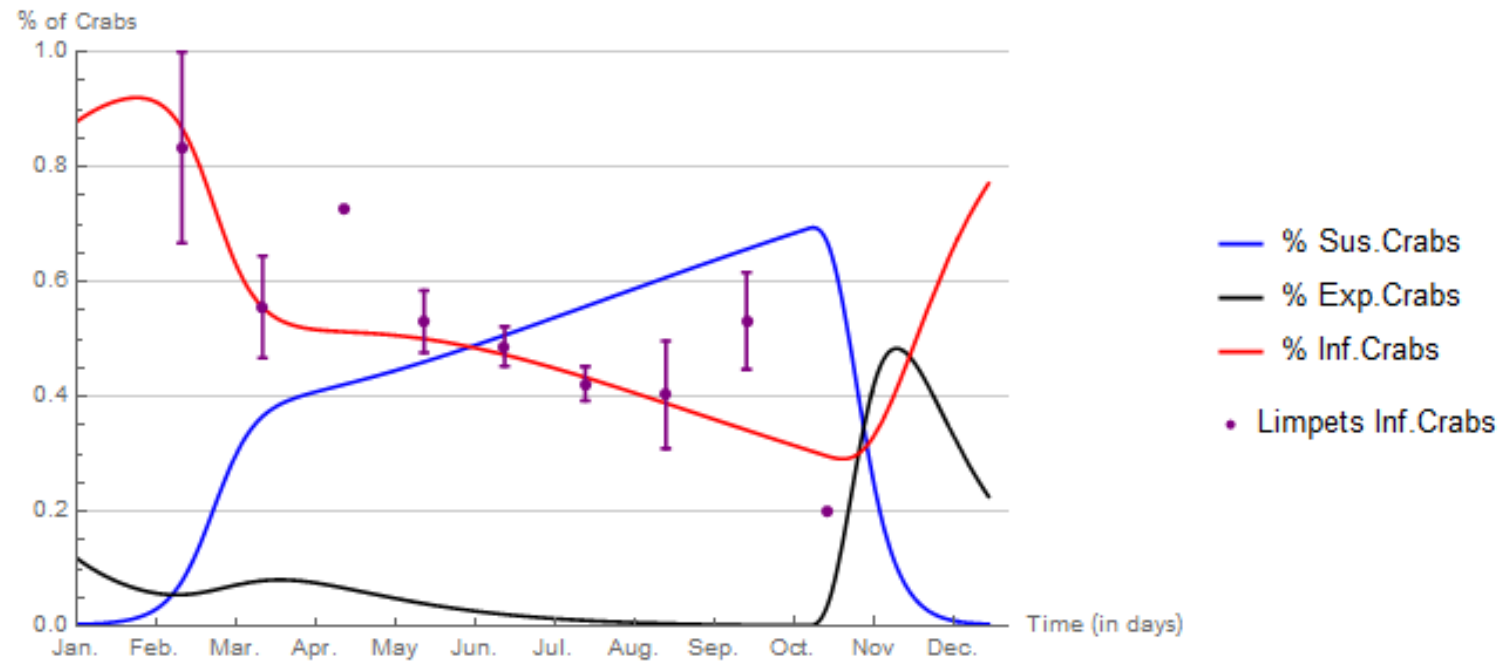

Figure 12: Percentage of crab populations from simulation and from observed data

In the summer, when birds are not present, the number of susceptible crabs increases, while the number of infected crabs decreases due to death and the number of exposed crabs becomes very small (very few eggs present in the sea). When birds are present, the susceptible crab population decreases, and then the number of exposed crabs increases first (due to more eggs produced through the feces of infected birds). After a delay, due to the parasite development stage from egg to juvenile, the number of infected crabs increases. Even though the number of exposed crabs goes down, there is still a little delay until the infection goes down, as the birds leave the coast and as some individuals are removed through mortality. When bird populations migrate out, approximately $90 \%$ of the crabs are now infected. Thus, there are very few new infections among crabs at this point. Without birds, the parasite life cycle is broken, and there is no new infection (and no new exposure) occurring (because no new parasite eggs), allowing crab population to grow toward its carrying capacity until the birds come back again.

The LiMPETS crab data, represented by the mean value with the standard error (Figure 9), shows a similar scenario. There is a high number of infected crabs during the 
season when the birds are leaving. The number of infected crabs roughly stays constant when the birds are absent, and starts going up until the birds arrive again. Our model seems to match with the pattern of observed infected crabs. Moreover, most of the mean values of the observed infected crabs are very close to the predicted infected crabs (Figure 12). This tells us that our model captures essential factors related to this biological system.

\section{EN Influence on Infected Crabs Prevalence}

Finally, we assessed the influence of EN on the prevalence of infected crabs using the LiMPETS data described earlier. To the data, we added a column for the temperature at the time when crabs were collected. Based on the date of collection, we found the corresponding temperature [80].

For this part of the study, we only used the temperature and the percentage of infected crabs at the Ocean Beach. Then we split the data again into three: EN, LN and regular (Reg.) years (Figure 4).

We obtained a regression model and a graph corresponding to each year.

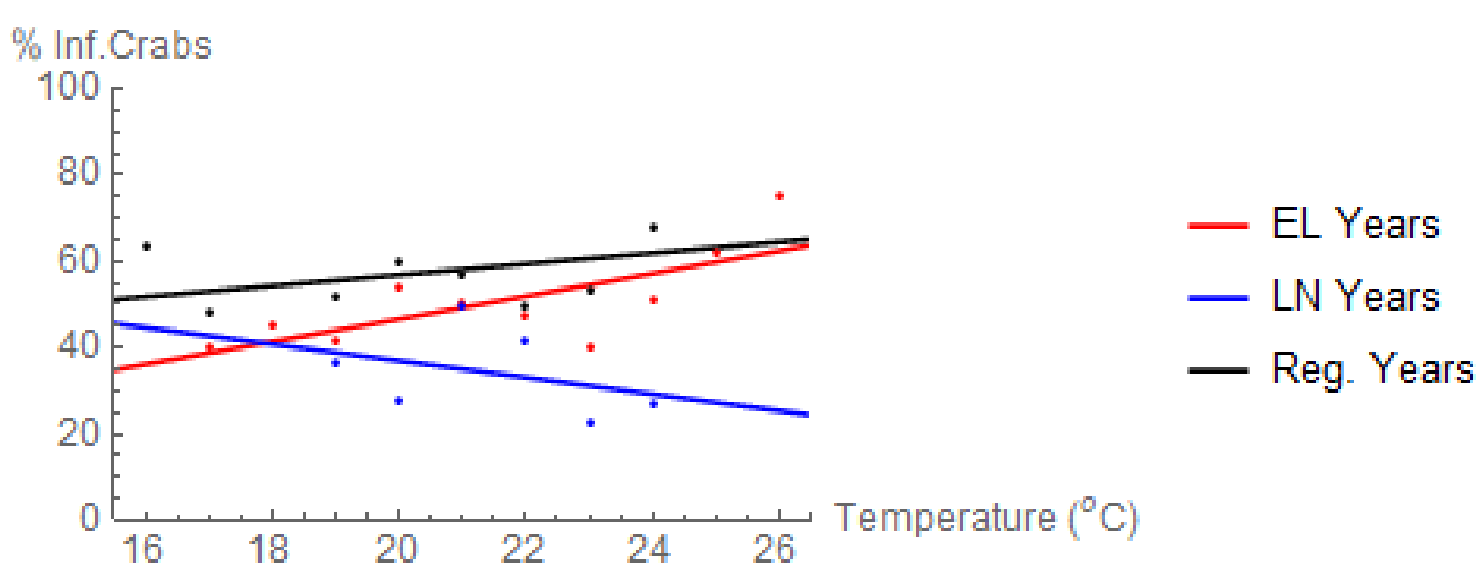

Figure 13: Relationship between infected crab prevalence and the temperature 
The equations of the regression models are:

El Niño years: $Y=-5.97+2.63 * X$,

Regular years: $Y=31.50+1.27 * X$, and

La Niña years: $Y=75.54-1.93 * X$.

Based on the coefficients of the linear regression between the percentage of infected crabs $(\mathrm{Y})$ and the temperature $(\mathrm{X})$, we have different values for the slope. Now, we need to check if these coefficients are significantly different from zero. In order to do that, we run a regression slope test, which is a simple two-sided t-test comparing the slope of the regression to zero. Our hypothesis is:

$$
\begin{aligned}
& H_{O}: \text { slope }=0, \text { and } \\
& H_{A}: \text { slope } \neq 0 .
\end{aligned}
$$

Here is a statistical summary of the regression for EN:

Table 6: EN linear regression slope test summary

\begin{tabular}{ccccc}
\hline \hline Variable & Coefficient & Std Error & t-statistic & P-value \\
\hline Intercept & -5.975 & 18.977 & -0.314 & 0.761 \\
\hline Slope & 2.63 & 0.875 & 3.008 & 0.017 \\
\hline
\end{tabular}

We obtain a probability value of 0.017 (see Table 6), less than $2.5 \%$. At $5 \%$ level of significance, we reject the null hypothesis. Therefore, the slope is significantly different from zero. Moreover, we conclude that all slopes are significantly different from each other. Hence, we conclude that during EN years, the number of infected crabs increases more rapidly (twice) than during regular years. Conversely, the number of infected crabs decreases during LN years. This result tells us that whenever temperature gets warmer than usual, the prevalence of infected crabs increases. However, the infection in the bird 
populations is subject to increase with the abundance of infected crabs along the coast, therefore temperature rise certainly influences bird abundance. This supports our hypothesis that El Niño increases the abundance of infected crabs prevalence along the Californian coast.

\section{Conclusion}

Since studies show that warmer temperatures increase the abundance of crabs and acanthocephalan parasites as well as change the timing of bird migration along the California coast [2], we investigated the difference in EN/LN temperatures using NOAA data and found that their mean temperatures are significantly different. Then, we connected warm temperatures to crab infections by showing that EN strongly increases the prevalence of crab infections along the coast using LiMPETS data. These two results support our hypotheses that EN and LN are significantly different and that El Niño increases the prevalence of infected crabs along the California coast. With a rise in sea temperature, the abundance of sand crabs and parasites increase, which creates an opportunity for more predators. As birds arrive at the coast earlier and leave later than usual, we can argue -only based on these results- that as the number of infected crabs increases, so will the number of infected birds. 


\section{CHAPTER IV \\ CONCLUDING REMARKS}

El Niño is a natural and complex weather pattern that occurs every two to five years and results to an increase in the ocean temperatures from the normal in the Pacific Ocean near the equator [29]. Unfortunately, a small change in temperature leads to enormous changes in our environment [87]. A recent study showed that temperature change across seasons and years influenced numerous host-parasite interactions [79]. Also, the change in the climate is expected to greatly impact the magnitude and frequency of disease transmission in both wildlife and human populations $[81,82,83]$. However, to develop a mathematical model of wildlife disease, it is essential to consider seasonal temperature patterns $[84,85,79]$.

In this paper, we first built a mathematical model using a system of differential equations that relates all hosts in the biological system with temperature-dependent (parasite development time) as well as time-dependent parameters (e.g., immigration and emigration at the Californian coast). We used the LiMPETS data [40] and sensitivity analysis to help parametrize the model. Once the model was built and parametrized, we investigated its performance through Floquet theory and found out that our nonlinear model produced stable periodic orbits. Since we expected difference in the impact during EN years versus none-EN (LN and regular years), we performed statistical analysis on a data set obtained from NOAA [41] to show the difference in temperatures in EN and LN years. Then, we performed another statistical analysis on the data from LiMPETS to show the difference in infected crab prevalence in EN/LN years. As a result, we found that as the temperature increases, the number of infected crabs increases. Finally, only based on the 
fact that birds spend more time on the coast during warmer temperatures [44] for resting and food, we made an argument that as the percentage prevalence of infected crab increases, so will the number of infected birds. Our statistical analyses support our hypotheses that El Niño and La Niña temperatures have different effects and that El Niño greatly impacts the prevalence of crab infections from acanthocphalan parasites along the California Coast.

This model has the potential to provide important information on protecting seabirds and other marine animals involved in the completion of the acanthocephalan parasite life cycle, if we are able to connect it to infected birds in El Niño and La Niña years.

\section{Future Directions}

The next step is to connect our mathematical model to the information we have from crab abundance in EN/LN years. This will probably help us, based on prey/predation relationship, to connect the model to infected birds and therefore study the direct influence of El Niño on the abundance of shorebirds along the Californian coast.

In our model, we assumed that temperature is affected only the development of the parasites from the egg to juvenile stage and that bird migration and crab reproduction are time-dependent. Birds migrate during specific times in a year. In general, spring migration begins in March, when it is warmer, and fall migration starts mid-to-late October, when it starts to get cold [2]. Besides the seasons, these migrations are associated with certain temperatures. During El Niño, the global temperature is warmer than usual. As a result, this change influences birds' migration routes and the annual migration rhythm, and could shorten or extend their journey [96]. In fact, during EN years, the spring becomes warmer and even starts earlier in some regions, leading to an earlier arrival and possibly a late departure of many birds. Hence, we could relate migration to temperature, which could allow us to alter our approach to bird abundance in the California coast during EN 
episodes.

Another interesting factor that could impact the abundance of the birds is climate change. $\mathrm{EN}$ is known to contribute to an increase in the global temperature, but does climate change in turn intensify EN episodes? Michael Jarraud, former Secretary-General of the World Meteorological Organization, said that "This naturally occurring El Niño event and human-induced climate change may interact and modify each other in ways we have never before experienced" [86]. With high confidence, scientists predict a rise of the global temperatures for coming decades. Intergovernmental Panel on Climate Change (IPCC), an international organization with thousands of scientists from all over the world, forecasts a rise of $2.5^{\circ}$ to $10^{\circ}$ Fahrenheit over the next century [87]. If a positive relationship between EN and climate change appears to exist, a rapid action should be taken to protect and conserve migratory birds as well as other temperature-sensitive animals. 


\section{REFERENCES}

[1] Surf Scoter Life Expectancy. (2017). Retrieved from http://www.worldlifeexpectancy.com/bird-life-expectancy-surf-scoter

[2] Anderson, E. M., Dickson, R. D., Lok, E. K., Palm, E. C., Savard, J. P. L., Bordage, D., \& Reed, A. (2015). Surf Scoter (Melanitta perspicillata). The Birds of North America Online. Cornell Lab of Ornithology, Ithaca, NY. doi, 10.

[3] Anderson, E. M., Esler, D., Boyd, W. S., Evenson, J. R., Nysewander, D. R., Ward, D. H., ... \& Hupp, J. W. (2012). Predation rates, timing, and predator composition for scoters (Melanitta spp.) in marine habitats. Canadian journal of zoology, 90(1), 42-50.

[4] De La Cruz, S. E., Takekawa, J. Y., Spragens, K. A., Yee, J., Golightly, R. T., Massey, G., ... \& Ziccardi, M. (2013). Post-release survival of surf scoters following an oil spill: an experimental approach to evaluating rehabilitation success. Marine pollution bulletin, 67(1), 100-106.

[5] Uher-Koch, B. (2013). Latitudinal and seasonal variation in non-breeding survival of surf and white-winged scoters (Doctoral dissertation, Science: Biological Sciences Department).

[6] Uher-Koch, B. D., Esler, D., Dickson, R. D., Hupp, J. W., Evenson, J. R., Anderson, E. M., ... \& Schmutz, J. A. (2014). Survival of surf scoters and white-winged scoters during remigial molt. The Journal of Wildlife Management, 78(7), 1189-1196.

[7] Accurso, L. M. (1992). Distribution and abundance of wintering waterfowl on San Francisco Bay, 1988-1990 (Doctoral dissertation, Humboldt State University).

[8] Collins, D.P., Trost, R.E., 2009. 2009 Pacific Flyway Data Book. U.S. Fish and Wildlife Service, Division of Migratory Bird Management, Portland, OR, pp. 145.

[9] Pitkin, M. and Wood, J. (Editors). 2011. The State of the Birds, San Francisco Bay. PRBO Conservation Science and the San Francisco Bay Joint Venture

[10] De La Cruz, S. E., Eadie, J. M., Miles, A. K., Yee, J., Spragens, K. A., Palm, E. C., \& Takekawa, J. Y. (2014). Resource selection and space use by sea ducks during the non-breeding season: Implications for habitat conservation planning in urbanized estuaries. Biological conservation, 169, 68-78.

[11] Sea Otter. (2017, June 26). Retrieved from http://www.nationalgeographic.com/animals/mammals/s/sea-otter/ 
[12] Media, W. (n.d.). Why are Sea Otters Important? No Sea Otters. No Kelp Forests. (2013). Retrieved from http://seaotters.com/2013/05/why-are-sea-otters-important-nosea-otters-no-kelp-forests/

[13] Black Scoter. (n.d.). Retrieved from http://seaducks.org/ducks/Black\%20Scoter

[14] Sand Crabs =). (n.d.). Retrieved from http://pacificsandcrabs.tumblr.com/

[15] Bilateria-1. (n.d.). Retrieved from http://palaeos.com/metazoa/bilateria.htm

[16] (n.d.). Retrieved from http://ggweather.com/enso/oni.htm

[17] Student Handout. Acanthocephalan Parasites: Fact Sheet (2010). Retrieved from http://limpets.org/wp-content/uploads/2015/01/AcanthoParasiteFS_Oct2010.pdf

[18] Farallones Marine Sanctuary Association. Acanthocephalan Parasites: Investigation in Pacific Mole Crabs. (2002). Retrieved from http://www.cabrillo.edu/ jcarothers/ecology/EcoWebSite/lab/Parasite_Lab.pdf

[19] Dugan, J. E., Hubbard, D. M., \& Lastra, M. (2000). Burrowing abilities and swash behavior of three crabs, Emerita analoga Stimpson, Blepharipoda occidentalis Randall, and Lepidopa californica Efford (Anomura, Hippoidea), of exposed sandy beaches. Journal of Experimental Marine Biology and Ecology, 255(2), 229-245.

[20] Efford, I. E. (1969). Egg size in the sand crab, Emerita analoga (Decapoda, Hippidae). Crustaceana, 16(1), 15-26.

[21] Jaramillo, E., Dugan, J., \& Contreras, H. (2000). Abundance, tidal movement, population structure and burrowing rate of Emerita analoga (Anomura, Hippidae) at a dissipative and a reflective sandy beach in south central Chile. Marine Ecology, 21(2), 113-127.

[22] Efford, I. E. (1976). Distribution of the sand crabs in the genus Emerita (Decapoda, Hippidae). Crustaceana, 169-183.

[23] Student Handout. The Pacific Mole Crab: Fact Sheet (2010). Retrieved from http://limpets.org/wp-content/uploads/2015/01/PacificMoleCrabFS_Oct2010.pdf

[24] Flores and Sanchez (2007). Retrieved from http://cssf.usc.edu/History/2007/Projects/S1903.pdf

[25] Klein, S. L. (2003). Parasite manipulation of the proximate mechanisms that mediate social behavior in vertebrates. Physiology \& behavior, 79(3), 441-449.

[26] Combes, C. (1991). Ethological aspects of parasite transmission. The American Naturalist, 138(4), 866-880.

[27] Combes, C. (1995). Interactions durables: Ãl'cologie et Ãlvolution du parasitisme 
(Vol. 26). Paris: Masson.

[28] Poulin, R. (1995). âĂIJAdaptiveâĂ A critical review. International journal for parasitology, 25(12), 1371-1383.

[29] US Department of Commerce, National Oceanic and Atmospheric Administration. (2009). What are El Nino and La Nina? Retrieved from http://oceanservice.noaa.gov/facts/ninonina.html

[30] Arntz, W. (2002). The role of El NiÃśo, La NiÃśa and climate change in the Pacific Eastern Boundary Currents: An integrated introductory view. Investigaciones marinas, 30(1), 81-82.

[31] Poulin, R. (2006). Global warming and temperature-mediated increases in cercarial emergence in trematode parasites. Parasitology, 132(1), 143-151.

[32] Poulin, R., \& Mouritsen, K. N. (2006). Climate change, parasitism and the structure of intertidal ecosystems. Journal of Helminthology, 80(2), 183-191.

[33] Arntz, W. E., Gallardo, V. A., GutiÃlrrez, D., Isla, E., Levin, L. A., Mendo, J., \& Wolff, M. (2006). El NiÃśo and similar perturbation effects on the benthos of the Humboldt, California, and Benguela Current upwelling ecosystems. Advances in geosciences, 6, 243-265.

[34] Oliva, M.E., I. Barrios, S. Thatje \& J. Laudien. 2008. Changes in Prevalence and Intensity of Infection of Profilicollis altmani (Perry, 1942) cystacanth (Acanthocephala) Parasitizing the Mole Crab Emerita analoga (Stimpson, 1857): an El Nino Cascade Effect? Helgoland Mar. Res. 62 (Suppl 1): S57-S62. doi: $10.1007 / \mathrm{s} 10152-007-0082-7$

[35] Fiedler, P. C. (2002). Environmental change in the eastern tropical Pacific Ocean: review of ENSO and decadal variability. Marine Ecology Progress Series, 244, 265-283.

[36] Mouritsen, K. N., \& Poulin, R. (2002). Parasitism, climate oscillations and the structure of natural communities. Oikos, 97(3), 462-468.

[37] Marcogliese, D. J. (2005). Parasites of the superorganism: Are they indicators of ecosystem health?. International journal for parasitology, 35(7), 705-716.

[38] Krach, M. (2015). Little Crabs in a Big Storm âĂŞ LiMPETS. Retrieved from http://limpets.org/little-crabs-in-a-big-storm/

[39] Tokeson, J. P., \& Holmes, J. C. (1982). The Effects of Temperature and Oxygen on the Development of Polymorphus marilis (Acanthocephala) in Gammarus lacustris (Amphipoda). The Journal of Parasitology, 68(1), 112. doi:10.2307/3281332 
[40] LiMPETS Data Management. (2016). Retrieved July 03, 2017, from http://sandybeach.limpets.org/app/data/sandcrab

[41] NOAA. (n.d). Retrieved from http://www.cpc.noaa.gov/products/analysis_monitoring/ensostuff/detrend.nino34.ascii.txt

[42] Surf Scoter. (2015). Retrieved from http://ca.audubon.org/birds-0/surf-scoter

[43] Seasons in the Sea. (2017). Retrieved from http://www.seasonsinthesea.com/apr/seabirds.shtml

[44] De La Cruz, S. E. W., Takekawa, J. Y., Wilson, M. T., Nysewander, D. R., Evenson, J. R., Esler, D., ... \& Ward, D. H. (2009). Spring migration routes and chronology of surf scoters (Melanitta perspicillata): a synthesis of Pacific coast studies. Canadian Journal of Zoology, 87(11), 1069-1086.

[45] Alerstam, T., \& LindstrÃúm, Ã ̌́. (1990). Optimal bird migration: the relative importance of time, energy, and safety. Bird migration: physiology and ecophysiology, 3317351 .

[46] Farmer, A. H., \& Wiens, J. A. (1998). Optimal migration schedules depend on the landscape and the physical environment: a dynamic modeling view. Journal of Avian Biology, 405-415.

[47] Farmer, A. H., \& Wiens, J. A. (1999). Models and Reality: Time-Energy Trade-Offs in pectoral sandpiper (calidris melanotos) migration. Ecology, 80(8), 2566-2580.

[48] Vrugt, J. A., Van Belle, J., \& Bouten, W. (2007). Pareto front analysis of flight time and energy use in longâĂŘdistance bird migration. Journal of Avian Biology, 38(4), $432-442$.

[49] Drent, R. H., Fox, A. D., \& Stahl, J. (2006). Travelling to breed. Journal of Ornithology, 147(2), 122-134.

[50] Drent, R. H., Eichhorn, G., Flagstad, A., Van der Graaf, A. J., Litvin, K. E., \& Stahl, J. (2007). Migratory connectivity in Arctic geese: spring stopovers are the weak links in meeting targets for breeding. Journal of ornithology, 148, 501-514.

[51] Larsson, K., Black, J. M., \& Prop, J. (2007). Wild goose dilemmas: population consequences of individual decisions in barnacle geese. Branta Press.

[52] Anderson, Eric M., Rian D. Dickson, Erika K. Lok, Eric C. Palm, Jean-Pierre L. Savard, Daniel Bordage and Austin Reed.(2015).Surf Scoter (Melanitta perspicillata), The Birds of North America (P. G. Rodewald, Ed.). Ithaca: Cornell Lab of Ornithology; Retrieved from the Birds of North America: https://birdsna.org/Species-Account/bna/species/sursco DOI: 10.2173/bna.363 
[53] Stewart, R.B., E. Wheaton, and D.L. Spittlehouse. 1998. Climate change: implications for the Boreal forest. In: Emerging Air Issues for the 21st Century: The Need for Multidisciplinary Mangement, Proceedings of a Speciality Conference, Sep. 22-24, 1997, Calgary, AB, Legge, A.H. and L.L. Jones (eds.), Air and Waste Management Assoc., Pittsburg, PA, pp 86-101

[54] Harley, C. D., Randall Hughes, A., Hultgren, K. M., Miner, B. G., Sorte, C. J., Thornber, C. S., ... \& Williams, S. L. (2006). The impacts of climate change in coastal marine systems. Ecology letters, 9(2), 228-241.

[55] TeamLVA. Do the Crab Walk (2013). Retrieved from http://limpets.org/crab-walk/

[56] Labaude, S., Rigaud, T., \& CÃlzilly, F. (2015). Host manipulation in the face of environmental changes: Ecological consequences. International Journal for Parasitology: Parasites and Wildlife, 4(3), 442-451.

[57] MacLeod, C. D., \& Poulin, R. (2012). HostâĂŞparasite interactions: a litmus test for ocean acidification?. Trends in parasitology, 28(9), 365-369.

[58] Marcogliese, D. J. (2001). Implications of climate change for parasitism of animals in the aquatic environment. Canadian Journal of Zoology, 79(8), 1331-1352.

[59] Morley, N. J., \& Lewis, J. W. (2014). Temperature stress and parasitism of endothermic hosts under climate change. Trends in parasitology, 30(5), 221-227.

[60] Lv, S., Zhou, X. N., Zhang, Y. I., Liu, H. X., Zhu, D., Yin, W. G., ... \& Jia, T. W. (2006). The effect of temperature on the development of Angiostrongylus cantonensis (Chen 1935) in Pomaceacanaliculata (Lamarck 1822). Parasitology research, 99(5), 583-587.

[61] Images, P. B. (2015, August 25). Sea Temperature Rise - Pristine Seas. Retrieved from http://www.nationalgeographic.com/environment/oceans/critical-issues-seatemperature-rise/

[62] Franceschi, N., Cornet, S., Bollache, L., DechaumeâĂ̌̌Moncharmont, F. X., Bauer, A., Motreuil, S., \& Rigaud, T. (2010). Variation between populations and local adaptation in acanthocephalan-induced parasite manipulation. Evolution, 64(8), 2417-2430.

[63] Franceschi, N., Bauer, A., Bollache, L., \& Rigaud, T. (2008). The effects of parasite age and intensity on variability in acanthocephalan-induced behavioural manipulation. International journal for parasitology, 38(10), 1161-1170.

[64] Reese, E. (2010). La Nina Vs. El Nino. Retrieved from http://www.accuweather.com/en/weather-news/la-nina/38971

[65] Pannell, D. J. (1997). Sensitivity analysis of normative economic models: theoretical 
framework and practical strategies. Agricultural economics, 16(2), 139-152.

[66] Baird, B. F. (1989). Managerial decisions under uncertainty: An introduction to the analysis of decision making (Vol. 4). John Wiley \& Sons.

[67] Cobelli, C., \& Romanin-Jacur, G. (1976). Controllability, observability and structural identifiability of multi input and multi output biological compartmental systems. IEEE Transactions on Biomedical Engineering, (2), 93-100.

[68] Cobelli, C., \& DiStefano, J. J. (1980). Parameter and structural identifiability concepts and ambiguities: a critical review and analysis. American Journal of Physiology-Regulatory, Integrative and Comparative Physiology, 239(1), R7-R24.

[69] Hamby, D. M. (1994). A review of techniques for parameter sensitivity analysis of environmental models. Environmental monitoring and assessment, 32(2), 135-154.

[70] Hoffman, F. O., \& Gardner, R. H. (1983). Evaluation of uncertainties in environmental radiological assessment models. Radiological Assessments: A Textbook on Environmental Dose Assessment, 11-1.

[71] Bauer, L. R., \& Hamby, D. M. (1991). Relative sensitivities of existing and novel model parameters in atmospheric tritium dose estimates. Radiation protection dosimetry, 37(4), 253-260.

[72] Krieger, T. J., Durston, C., \& Albright, D. C. (1978). Statistical determination of effective variables in sensitivity analysis. Transactions of the American Nuclear Society, 28.

[73] Klausmeier, C. A. (2008). Floquet theory: a useful tool for understanding nonequilibrium dynamics. Theoretical Ecology, 1(3), 153-161.

[74] Nisbet, R. M., \& Gurney, W. (1982). Modelling fluctuating populations. Wiley, New York.

[75] DeAngelis, D. L., \& Waterhouse, J. C. (1987). Equilibrium and nonequilibrium concepts in ecological models. Ecological monographs, 57(1), 1-21.

[76] Teschl, G. (2000). Ordinary differential equations and Dynamical Systems. Lecture Notes, University of Vienna.

[77] Chesson, P. (1994). Multispecies competition in variable environments. Theoretical Population Biology, 45(3), 227-276.

[78] Kooi, B. W., \& Troost, T. A. (2006). Advantage of storage in a fluctuating environment. Theoretical population biology, 70(4), 527-541.

[79] Peirce, J. P., Sandland, G. J., Bennie, B., \& Haro, R. J. (2016). Modeling and analysis of a temperature-driven outbreak of waterfowl disease in the Upper Mississippi River. 
Ecological Modelling, 320, 71-78.

[80] Historical Weather. (2017). Retrieved from https://www.wunderground.com/history/?MR=1

[81] Glick, P., Stein, B., \& Edelson, N. A. (2010). Scanning the conservation horizon: a guide to climate change vulnerability assessment. National Wildlife Federation, Washington DC.

[82] Mangal, T. D., Paterson, S., \& Fenton, A. (2008). Predicting the impact of long-term temperature changes on the epidemiology and control of schistosomiasis: a mechanistic model. PLoS one, 3(1), e1438.

[83] Rohr, J. R., Dobson, A. P., Johnson, P. T., Kilpatrick, A. M., Paull, S. H., Raffel, T. R., ... \& Thomas, M. B. (2011). Frontiers in climate changeâĂŞdisease research. Trends in ecology \& evolution, 26(6), 270-277.

[84] Altizer, S., Dobson, A., Hosseini, P., Hudson, P., Pascual, M., \& Rohani, P. (2006). Seasonality and the dynamics of infectious diseases. Ecology letters, 9(4), 467-484.

[85] Oraby, T., Vasilyeva, O., Krewski, D., \& Lutscher, F. (2014). Modeling seasonal behavior changes and disease transmission with application to chronic wasting disease. Journal of theoretical biology, 340, 50-59.

[86] Cho, R. Earth Institute, Columbia University. (2016). El Nino and global warming-what's the connection? Retrieved from https://phys.org/news/2016-02-el-nino-global-warmingwhat.html

[87] Global Climate Change. (2017). The Consequences of Climate Change . Retrieved from https://climate.nasa.gov/effects/

[88] Laidre, K. L., Jameson, R. J., \& DeMaster, D. P. (2001). An estimation of carrying capacity for sea otters along the California coast. Marine Mammal Science, 17(2), 294-309.

[89] Monterey Bay Aquarium Foundation. Sand crab. (2017). Retrieved from https://www.montereybayaquarium.org/animal-guide/invertebrates/sand-crab

[90] Sandland, G. J., \& Minchella, D. J. (2003). Effects of diet and Echinostoma revolutum infection on energy allocation patterns in juvenile Lymnaea elodes snails. Oecologia, 134(4), 479-486.

[91] Negus, M. R. (1998). A Life Table for the fresh water mollusc Bithynia tentaculata (L.). Journal of Biological Education, 32(1), 14-23.

[92] Richter, T. (2001). Reproductive biology and life history strategy of Bithynia tentaculata (Linnaeus, 1758) and Bithynia leachii (Sheppard, 1823). Ph Dissertation, 
Fac. Biology, Univ. Hannover, 167pp.

[93] Murray, D., \& Karl, M. (n.d.). Parasitic Helminth (Acanthocephalan) Infection as a Cause of Mortality in the California Sea Otter (Enhydra lutris). Retrieved from http://www.vin.com/apputil/content/defaultadv1.aspx?pId=11257\&id=3864439\&print=1

[94] Smith, N. F. (2007). Associations between shorebird abundance and parasites in the sand crab, Emerita analoga, along the California coast. Journal of Parasitology, 93(2), 265-273.

[95] Mayer, K. A., Dailey, M. D., \& Miller, M. A. (2003). Helminth parasites of the southern sea otter Enhydra lutris nereis in central California: abundance, distribution and pathology. Diseases of aquatic organisms, 53(1), 77-88.

[96] Adams, A. (2017). Climate change and migratory birds. Retrieved from http://www.worldmigratorybirdday.org/2007/index44cb.html

[97] Armstrong, R.A., \& McGehee, R. (1980). Competitive exclusion. Am Nat 115:151âĂŞ170.

[98] Litchman, E., \& Klausmeier, C. A. (2001). Competition of phytoplankton under fluctuating light. The American Naturalist, 157(2), 170-187.

[99] May, R.M. (1974) Stability and complexity in model ecosystems, 2nd edn. Princeton University Press, Princeton. 


\section{APPENDIX A \\ MATHEMATICA CODES}

The Mathematica Codes used for the thesis research are below:

*Import the temperature data from NOAA and name it temp $1950 *$ temp1950 = Import ["1ocation"];

*Interpolating the temperature data*

$\mathrm{T}=$ Interpolation [ temp1950];

Plot $[\mathrm{T}[\mathrm{t}], \quad\{\mathrm{t}, 0$,

Length [ temp1950]\},

(* NOTE: $\mathrm{t}$ is measured in months starting t0 = Jan $1950 *$ )

Ticks $\rightarrow\{\{\{0 * 12, " 1950 "\},\{10 * 12, " 1960 "\},\{20 * 12, " 1970 "\}$

$,\{30 * 12, " 1980 "\},\{40 * 12, " 1990 "\},\{50 * 12, " 2000 "\},\{60 * 12$,

"2010" \} , Automatic $\},$ AxesLabel $\rightarrow$ \{"Time (in days)",

"Temperature (in Celsius)" \}]

TempYear $\left[\right.$ year $\left.r_{-}\right]:=$Interpolation $[$Take $[$temp1950, $\{1+$

$($ year -1950$) * 12,12+($ year -1950$) * 12,1\}]]$

PlotTempYear [year_] := Plot [TempYear[year $[\mathrm{t}]$,

$\{\mathrm{t},($ year -1950$) * 12,12+($ year -1950$) * 12\}$,

Ticks $\rightarrow\{\{\{($ year -1950$) * 12$, "Jan" $\},\{1+($ year -1950$)$

*12, "Feb" $\},\{2+($ year -1950$) * 12, "$ March" $\},\{3+$ (year

- 1950)*12, "April" $\},\{4$ + (year - 1950)*12, "May" $\}$,

$\{5+($ year -1950$) * 12$, "June" $\},\{6+($ year -1950$)$ 


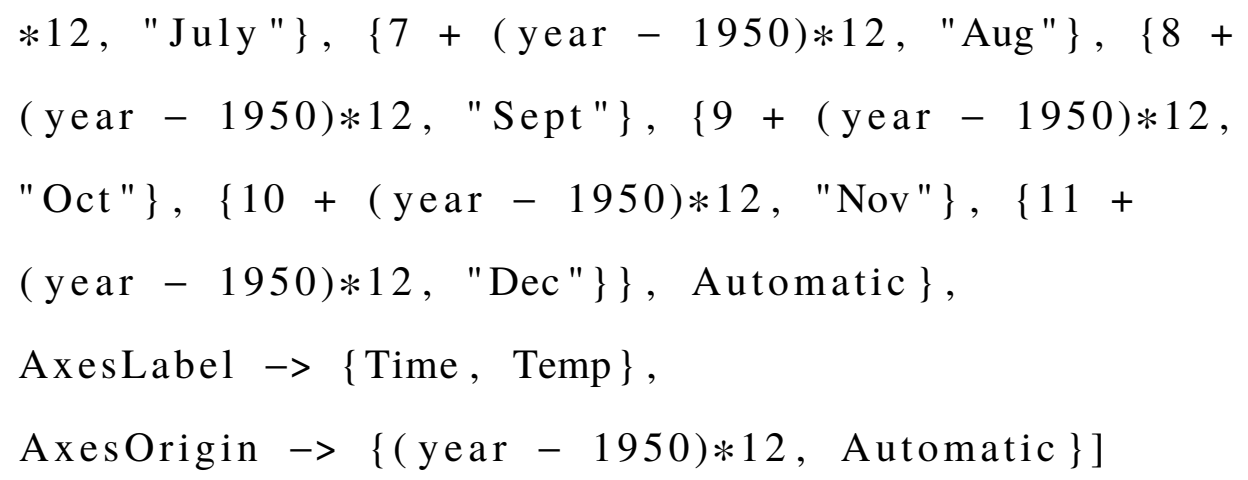

Plot [inmtime $[\mathrm{t}], \quad\{\mathrm{t}, 0,1 * 364.25\}$, PlotRange $\rightarrow$ All, Ticks $\rightarrow\{\{\{0 * 364.25 / 12$, "Jan" $\},\{1 * 364.25 / 12$, "Feb" $\}$,

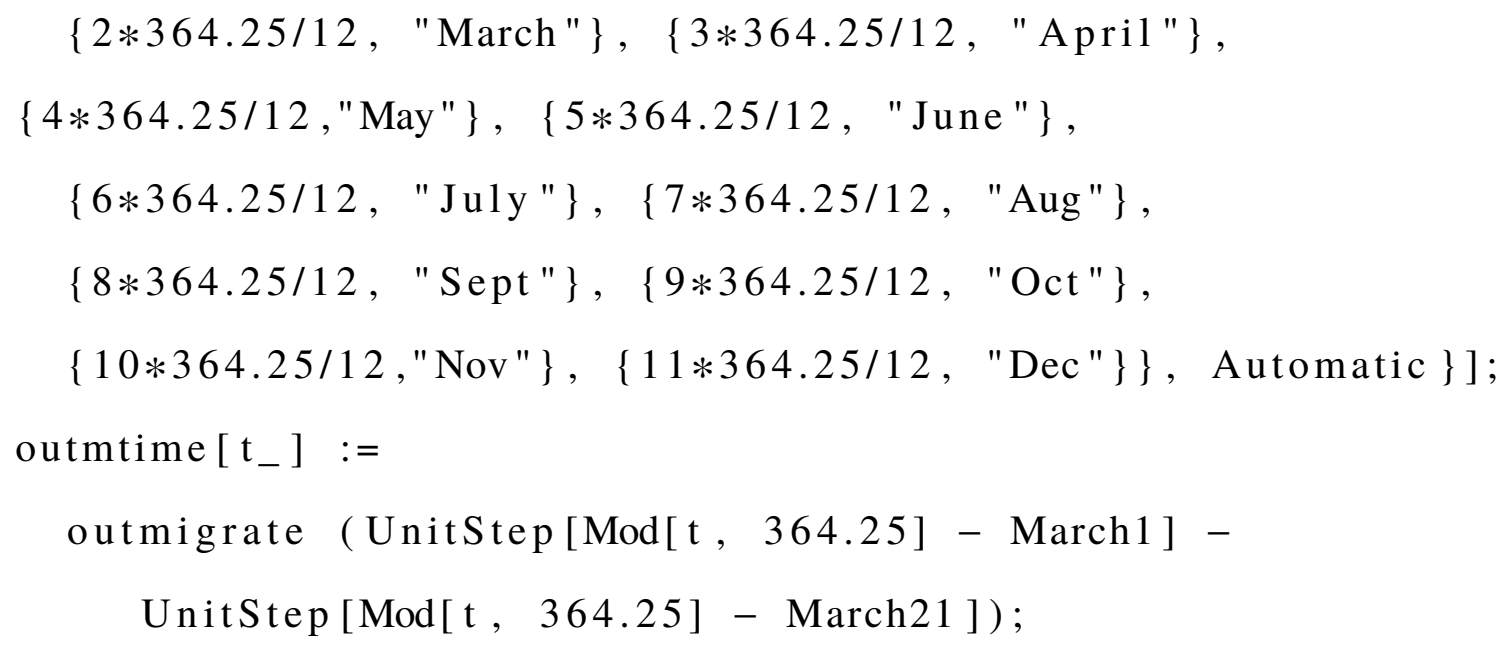


Ticks $\rightarrow\{\{\{0 * 364.25 / 12$, "Jan" $\},\{1 * 364.25 / 12$, "Feb" $\}$, $\{2 * 364.25 / 12, \quad$ March" $\},\{3 * 364.25 / 12$, "April ", $\{4 * 364.25 / 12$, "May" $\},\{5 * 364.25 / 12$, "June" $\}$, $\{6 * 364.25 / 12$, "July" $\}, \quad\{7 * 364.25 / 12, \quad$ "Aug" $\}$, $\{8 * 364.25 / 12, "$ Sept" $\}, \quad\{9 * 364.25 / 12, \quad$ Oct $"\}$, $\{10 * 364.25 / 12, " N o v "\},\{11 * 364.25 / 12, "$ Dec" $\}\}$, Automatic $\}]$; gamtemp [temperature $]:=(-2.002+0.216 *$ temperature $) / 100 ;$ Plot [gamtemp [TempYear[1950][t*(12/364.25)]], \{t, $0,364.25\}$, Ticks $\rightarrow\{\{\{0 * 30$, "Jan." $\},\{1 * 30$, "Feb." $\},\{2 * 30$, "March" $\}$, $\{3 * 30, "$ Apr." $\},\{4 * 30$, "May" $\},\{5 * 30$, "Jun." $\},\{6 * 30, \quad$ "Jul . $\}$, $\{7 * 30$, "Aug." $\},\{8 * 30$, "Sept." $\},\{9 * 30$, "Oct." $\}$, $\{10 * 30$, "Nov." $\},\{11 * 30$, "Dec." $\}\}$, Automatic $\}$, AxesLabel $\rightarrow\{$ "Time (in days)", "Temperature (in Celsius)" $\}$ ] // Quiet

*Define the system of differential equations* ode1 $=\mathrm{sb}^{\prime}[\mathrm{t}]==$ inmtime $[\mathrm{t}]-$ outmtime $[\mathrm{t}] * \mathrm{sb}[\mathrm{t}]-\operatorname{mub} * \mathrm{sb}[\mathrm{t}]$ - beta*sb[t]*infc[t]/( $\operatorname{sc}[\mathrm{t}]+\operatorname{exc}[\mathrm{t}]+\operatorname{infc}[\mathrm{t}])$; ode2 $=\operatorname{infb}{ }^{\prime}[\mathrm{t}]==\operatorname{beta} * \operatorname{sb}[\mathrm{t}] * \operatorname{infc}[\mathrm{t}] /(\operatorname{sc}[\mathrm{t}]+\operatorname{exc}[\mathrm{t}]$ $+\operatorname{infc}[t])-\operatorname{mub} * \operatorname{infb}[t]-\operatorname{kb} * \operatorname{infb}[t]$ ode3 $=\mathrm{sc}^{\prime}[\mathrm{t}]==\mathrm{rc} * \operatorname{sc}[\mathrm{t}](1-\mathrm{sc}[\mathrm{t}] / \mathrm{Kc})-\operatorname{xhi} * \operatorname{sc}[\mathrm{t}] * \operatorname{infb}[\mathrm{t}]$; ode $4=\operatorname{exc}{ }^{\prime}[\mathrm{t}]==\operatorname{xhi} * \operatorname{sc}[\mathrm{t}] * \operatorname{infb}[\mathrm{t}]-$ gamtemp [ $\mathrm{T}[\mathrm{t} *(12 / 364.25)]] * \operatorname{exc}[\mathrm{t}]$;

$\operatorname{ode} 5=\operatorname{infc}{ }^{\prime}[\mathrm{t}]==\operatorname{gamtemp}[\mathrm{T}[\mathrm{t} *(12 / 364.25)]] * \operatorname{exc}[\mathrm{t}]$

- muc*infc $[\mathrm{t}]-\mathrm{kc} * \operatorname{infc}[\mathrm{t}]$ ode $6=\operatorname{so}{ }^{\prime}[\mathrm{t}]==\operatorname{ro} * \operatorname{so}[\mathrm{t}](1-\operatorname{so}[\mathrm{t}] / \mathrm{Ko})-$ 
$\operatorname{rho} * \operatorname{so}[\mathrm{t}] * \operatorname{infc}[\mathrm{t}] /(\operatorname{sc}[\mathrm{t}]+\operatorname{exc}[\mathrm{t}]+\operatorname{infc}[\mathrm{t}])$

$\operatorname{ode} 7=\operatorname{info},[\mathrm{t}]==\operatorname{rho} * \operatorname{so}[\mathrm{t}] * \operatorname{infc}[\mathrm{t}] /(\operatorname{sc}[\mathrm{t}]+\operatorname{exc}[\mathrm{t}]$

$+\operatorname{infc}[\mathrm{t}])-\operatorname{muo} * \operatorname{info}[\mathrm{t}]-\operatorname{ko} * \operatorname{info}[\mathrm{t}]$

sol $=$ NDSolve $[\{\operatorname{ode} 1, \operatorname{ode} 2, \operatorname{ode} 3, \operatorname{ode} 4, \operatorname{ode} 5, \operatorname{ode} 6, \operatorname{ode} 7$, $\operatorname{sb}[0]==1000, \operatorname{infb}[0]==100 ., \operatorname{sc}[0]==1700$, infc $[0]==100 ., \operatorname{exc}[0]==0 .$, so $[0]==1600$, $\operatorname{info}[0]==0.\},\{\operatorname{sb}[\mathrm{t}], \operatorname{infb}[\mathrm{t}], \operatorname{sc}[\mathrm{t}], \operatorname{exc}[\mathrm{t}]$, $\operatorname{infc}[\mathrm{t}]$, so $[\mathrm{t}], \quad \operatorname{info}[\mathrm{t}]\}, \quad\{\mathrm{t}, \quad 0, \quad 10 * 364.25\}]$;

* Plot the number of susceptible and infected birds* Plot [Evaluate $[\{\mathrm{sb}[\mathrm{t}], \operatorname{infb}[\mathrm{t}]\} /$ sol $],\{\mathrm{t}, 7 * 364.25$, $8 * 364.25\}$, PlotRange $\rightarrow$ All, PlotStyle $\rightarrow\{$ Blue, Red $\}$, AxesLabel $\rightarrow$ \{"Time (in day)", "Number of Inf.Birds" \}, PlotLegends $\rightarrow$ \{"Sus.Birds", "Inf.Birds" $\}]$

*Import the data from LiMPETS and calculate mean and standard error of infected crab prevalence $*$ CrabPrevPerMoOB = Import["1ocation "];

MeanStdError $=\{\{0.8335,0.1665\},\{0.5558,0.08862133\}$, $\{0.727,0\},\{0.5304,0.054\},\{.4871, .03459\},\{.4224$, $0.0299\},\{0.403, .09375\},\{0.5314, .0844\},\{0.2,0\}\} ;$

Needs [" ErrorBarPlots " "] Year = 2;

MoMeanStdError $=\{\{\{$ Year $* 364.25+(364.25 / 12) * 2,0.8335\}$, ErrorBar $[0.1665]\},\{\{$ Year*364.25 + (364.25/12)*3,0.5558\}, ErrorBar $[0.08862133]\},\{\{$ Year*364.25 + (364.25/12)*4,0.727\}, ErrorBar $[0]\},\{\{$ Year $* 364.25+(364.25 / 12) * 5,0.5304\}$, 
ErrorBar $[0.054]\}, \quad\{\{$ Year*364.25+(364.25/12)*6,.4871\}, ErrorBar [.03459]\}, $\{\{$ Year*364.25 + (364.25/12)*7,.4224\}, ErrorBar [0.0299]\}, $\{\{$ Year*364.25 + $(364.25 / 12) * 8,0.403\}$, ErrorBar $[.09375]\},\{\{$ Year*364.25 $+(364.25 / 12) * 9,0.5314\}$, ErrorBar $[.0844]\},\{\{$ Year*364.25 + $(364.25 / 12) * 10,0.2\}$, ErrorBar $[0]\}\}$;

MoTickLabels $=\{\{\{$ Year*364.25 $+(364.25 / 12) * 1, "$ Feb" $\}$, $\{$ Year $* 364.25+(364.25 / 12) * 2$, "Mar" $\}, \quad\{$ Year $* 364.25+$ $(364.25 / 12) * 3, \quad$ Apr" $\},\{$ Year*364.25 + (364.25/12)*4, "May" $\},\{$ Year*364.25 + (364.25/12)*5, "Jun" \}, $\{$ Year*364.25 $+(364.25 / 12) * 6, " J u l "\}, \quad\{$ Year $* 364.25+$ $(364.25 / 12) * 7, \quad$ Aug" $\},\{$ Year*364.25 + (364.25/12)*8, "Sept" \}, \{Year*364.25 + (364.25/12)*9, "Oct" \} \}, Automatic \}; CrabPrevDataPlot $=$ ErrorListPlot $[$ MoMeanStdError, Joined $\rightarrow$ False, Frame $\rightarrow\{$ Left, Bottom $\}$, FrameTicks $\rightarrow$ MoTickLabels, PlotRange $\rightarrow$ Automatic, $\{0,1\}\}$, FrameLabel $\rightarrow$ \{None, Style ["\% Inf Crab", 12, FontFamily $\rightarrow$ "Arial"] $\}$, AxesLabel $\rightarrow\{$ "Time (in days)", "\%Inf.Crabs"\}]

* Plot the percentage of sus., exposed and inf. crabs* InfCrab $=\operatorname{Plot}[$ Evaluate $[\{\operatorname{sc}[t] /(\operatorname{sc}[t]+\operatorname{exc}[t]+\operatorname{infc}[t])$, $\operatorname{exc}[t] /(\operatorname{sc}[t]+\operatorname{exc}[t]+\operatorname{infc}[t])$, $\operatorname{infc}[t] /(\operatorname{sc}[t]+\operatorname{exc}[t]+\operatorname{infc}[t])\} /$ sol $]$, $\{\mathrm{t}, 2 * 364.25,3 * 364.25\}$, GridLines $\rightarrow\{\{\}$, Automatic $\}$, PlotRange $\rightarrow\{\{750,1100\},\{0,1\}\}$, 
PlotStyle $\rightarrow$ Blue, Black, Red \},

PlotLegends $\rightarrow\{" \%$ Sus.Crabs","\% Exp.Crabs","\% Inf.Crabs" $\}$, AxesLabel $\rightarrow\{$ "Time (in days)", "\% of Crabs"\}]

Show [ InfCrab , CrabPrevDataPlot ]

* Regression Model between temperature and inf. crabs* $\operatorname{lm} 1$ = LinearModelFit [ENData, $\mathrm{x}, \mathrm{x}$ ] Normal[ $\operatorname{lm} 1]$

p1 = Show [ListPlot[ENData, PlotStyle $\rightarrow$ Red $]$,

Plot $[\operatorname{lm} 1[x],\{x, 0,30\}$, PlotStyle $\rightarrow$ Red,

PlotLegends $\rightarrow\{$ EN Years $\}]$,

AxesLabel $\rightarrow\{$ Temperature, Inf. Crabs $\}$, Axes $\rightarrow$ True ]

$\operatorname{lm} 2=$ LinearModelFit [LNData, $\mathrm{x}, \mathrm{x}]$ Normal[ $\operatorname{lm} 2]$

p2 = Show[ListPlot[LNData, PlotStyle $\rightarrow$ Blue $],$

Plot $[\operatorname{lm} 2[x], \quad\{x, 0,30\}$, PlotStyle $\rightarrow$ Blue,

PlotLegends $\rightarrow\{$ LN Years $\}]$,

AxesLabel $\rightarrow$ TTemperature, Inf. Crabs $\}$, Axes $\rightarrow$ True]

$\operatorname{lm} 3=$ LinearModelFit [RegYears, $\mathrm{x}, \mathrm{x}]$ Normal[ $\operatorname{lm} 3$ ]

p3 = Show [ListPlot[RegYears, PlotStyle $\rightarrow$ Black],

Plot $[\operatorname{lm} 3[x],\{x, 0,30\}$, PlotStyle $\rightarrow$ Black,

PlotLegends $\rightarrow\{$ Reg. Years $\}]$,

AxesLabel $\rightarrow$ TTemperature, Inf. Crabs $\}$, Axes $\rightarrow$ True]

Show $[\mathrm{p} 1, \mathrm{p} 2, \mathrm{p} 3]$ 


\section{APPENDIX B \\ DATA SUMMARY}

Here is the summary of the data from LiMPETS.

Site: Ocean Beach. Total Crabs $=1,749$

Table B-1: LiMPETS data summary

\begin{tabular}{ccccc}
\hline \hline Year & Total \#crabs & \# Crabs with Parasite & Total \#Parasites & \% Inf.Crabs \\
2002 & 8.25 & 3.75 & 5.50 & 43.33 \\
2003 & 19.75 & 7.50 & 22.50 & 40.55 \\
2004 & 15.36 & 4.46 & 17.64 & 48.20 \\
2005 & 12.27 & 6.64 & 21.64 & 56.32 \\
2006 & 6.89 & 3.33 & 8.78 & 44.02 \\
2007 & 9.29 & 4.12 & 12.47 & 37.77 \\
2008 & 14.83 & 6.50 & 13.67 & 42.50 \\
2009 & 6.11 & 3.00 & 5.22 & 41.16 \\
2011 & 35.50 & 4.50 & 4.50 & 8.80 \\
2012 & 6.75 & 4.00 & 10.25 & 54.80 \\
2013 & 20.80 & 15.50 & 62.50 & 75.65 \\
2014 & 33.44 & 17.56 & 54.44 & 52.51 \\
2015 & 22.63 & 12.75 & 33.75 & 58.79 \\
2016 & 30.17 & 9.33 & 17.33 & 29.98 \\
\hline \multicolumn{5}{c}{ http $:$ //sandybeach.limpets.org/app/data/list }
\end{tabular}


We sort NOAA data according to EN/LN classification table and we found the mean and standard deviation (Std. Dev.) for each subcategory.

Table B-2: NOAA data summary sort by EN/LN in ${ }^{\circ} \mathrm{C}$

\begin{tabular}{ccccc}
\hline \hline Statistic & Weak EN & Strong EN & Weak LN & Strong LN \\
& 27.14 & 27.95 & 25.86 & 25.57 \\
& 27.35 & 27.92 & 26.23 & 25.43 \\
& 27.00 & 28.17 & 26.07 & 25.48 \\
27.41 & & 26.32 & \\
& 27.35 & & 25.99 & \\
& 27.14 & & 26.30 & \\
& 27.71 & & 26.13 & \\
& 27.75 & & 26.37 & \\
& 27.49 & & 26.37 & \\
& & & 26.49 & \\
& & & 26.25 & \\
Mean & 27.37 & 28.02 & 26.23 & 25.50 \\
Std.Dev. & 0.25 & 0.14 & 0.18 & 0.07 \\
hline & \multicolumn{4}{c}{ http : //sandybeach.limpets.org/app/data/list }
\end{tabular}

